\title{
Presuppositions, implicatures, and contextual equivalence
}

\author{
Paul Marty ${ }^{1}$ Jacopo Romoli ${ }^{2}$
}

Accepted: 24 March 2021 / Published online: 8 April 2021

(c) The Author(s) 2021

\begin{abstract}
Maximize Presupposition! (MP), as originally proposed in Heim (Semantik: Ein internationales Handbuch der zeitgenössischen Forschung, pp. 487-535, 1991) and developed in subsequent works, offers an account of the otherwise mysterious unassertability of a variety of sentences. At the core of MP is the idea that speakers are urged to use a sentence $\psi$ over a sentence $\phi$ if $\psi$ contributes the same new information as $\phi$, yet carries a stronger presupposition. While MP has been refined in many ways throughout the years, most (if not all) of its formulations have retained this characterisation of the MP-competition. Recently, however, the empirical adequacy of this characterisation has been questioned in light of certain newly discovered cases that are infelicitous, despite meeting MP-competition conditions. This has led some researchers to broaden the scope of MP, extending it to competition between sentences which are not contextually equivalent (Spector and Sudo in Linguistics and Philosophy 40(5):473-517, 2017) and whose presuppositions are not satisfied in the context (Anvari in Proceedings of Semantics and Linguistic Theory 28, pp. 711-726, 2018; Manuscript, IJN-ENS, 2019). In this paper, we present a body of evidence showing that these formulations of MP are sometimes too liberal, sometimes too restrictive: they overgenerate infelicity for a variety of felicitous cases while leaving the infelicity of minimally different cases unaccounted for. We propose an alternative, implicature-based approach stemming from Magri (PhD dissertation, MIT, 2009), Meyer (PhD dissertation, MIT, 2013), and Marty (PhD dissertation, MIT, 2017), which reintroduces contextual equivalence and presupposition satisfaction in some form through the notion of relevance. This approach is shown to account for the classical and most of the novel cases. Yet some of the latter remain problematic for this approach as well. We end the paper with a systematic comparison of the different approaches to MP and MP-like phenomena, covering both the classical and the novel cases. All in all, the issue of how to properly restrict the competition for MP-like phenomena remains an important challenge for all accounts in the literature.
\end{abstract}

For very helpful discussion and feedback, we would like to thank Amir Anvari, Christine Bartels, Patrick Elliott, Angelika Kratzer, Matt Mandelkern, Uli Sauerland, Benjamin Spector, Yasu Sudo, and an anonymous reviewer for NALS. This work was supported by the Leverhulme trust grant RPG-2018-425.

Extended author information available on the last page of the article 
Keywords Maximize Presupposition! · Presupposed Ignorance Principle · Logical Integrity · Exhaustivity · Presuppositions · Implicatures · Contextual equivalence · Relevance · Oddness

\section{Introduction}

The minimal pairs in (1)-(2) exemplify the long-standing observation originating in Heim (1991) that the utterance of a sentence $\phi$ is infelicitous in a context $c$ if $\phi$ has a presuppositionally stronger competitor $\psi$ whose presupposition is already common ground at $c$, i.e., mutually accepted by the interlocutors in $c$, and makes the same contribution as $\phi$ at $c$.

(1) Context: It is common ground that there is a unique sun.

a. \#A sun is shining.

b. The sun is shining.

(2) Context: It is common ground that John has two parents.

a. \#All of John's parents left.

b. Both of John's parents left.

Heim (1991) proposed to derive such contrasts from a general principle of language use which has come to be known as Maximize Presupposition! (MP henceforth), exhorting speakers to make their conversational contributions by 'presupposing as much as possible.' Since Heim's formulation of MP, many researchers have contributed to describing and refining the formal aspects of the competition at work in examples like (1)-(2), together with the contextual conditions on which this competition effectively leads to infelicity effects. A somewhat standard formulation of MP is given in (3).

\section{MAXIMIZE PRESUPPOSITION! (MP)}

A sentence $\phi$ is infelicitous in context $c$ if there is an alternative $\psi$ to $\phi$ such that:

a. $\quad \psi$ 's presupposition asymmetrically entails $\phi$ 's presupposition, and

b. $\psi$ 's presupposition is satisfied in $c$, and

c. $\psi$ and $\phi$ are contextually equivalent in $c$.

At the core of MP is the idea that cooperative speakers are urged to use a sentence $\psi$ over a sentence $\phi$ if, in the context of use, $\psi$ contributes the same new information as $\phi$, yet carries a stronger presupposition. This principle accounts for the contrasts in (1)-(2): in these examples, the (a)-sentences are deemed infelicitous by MP because they compete with the minimally different (b)-sentences, which convey the same information as their (a)-counterparts but carry stronger presuppositions that are satisfied in the relevant contexts. Thus, MP offers an account of the otherwise mysterious (un)assertability of a variety of sentences against given contextual information. Since the initial analysis of the motivating cases in (1)-(2), MP has been successfully applied to a variety of phenomena, and the classical picture sketched above has been extended and implemented in different versions (a.o., Percus 2006, 2010; Sauerland 2008; Chemla 2008; Schlenker 2012; Katzir and Singh 2013; Rouillard and Schwarz 
2017; Magri 2009; Marty 2017; Anvari 2019). Crucially, most (if not all) of its reformulations thus far have retained the three key ingredients of the classical formulation in (3). Recently, however, some new data have been brought to light that put these basic tenets in doubt. These data appear very similar to the ones licensed by MP on the received view, yet they are unexpectedly infelicitous. To accommodate these data, some researchers have proposed to relax the restrictions on the scope of phenomena MP was held to apply to: on their view, the competition in question should be extended to sentences which are not contextually equivalent (Spector and Sudo 2017) and whose presuppositions are not satisfied in the context (Anvari 2018, 2019).

In this paper, we present a body of evidence showing that these novel proposals are sometimes too liberal, sometimes too restrictive: they overgenerate infelicity for a variety of felicitous cases, while leaving the actual infelicity of seemingly similar cases unaccounted for. After presenting the challenges for MP and how the novel proposals address them in Sect. 2, we show in Sect. 3 that, despite their immediate successes, these proposals overgenerate specifically in cases involving (1) environments giving rise to existential presuppositions, (2) cardinal partitives, and (3) the restrictor of definites, universal quantifiers, which-phrases, and the antecedent of conditionals. In addition, we show that they undergenerate by not capturing the infelicity of infelicitous sentences carrying disjunctive presuppositions, building on cases observed by Spector and Sudo (2017). We argue that the culprit is precisely the fact that these novel principles drop or weaken some of the main ingredients of MP above, in particular the requirement of contextual equivalence. We move in Sect. 4 to propose an alternative approach based on implicatures, stemming from Magri 2009, Marty 2017, 2019b, and Marty and Romoli 2021, which reintroduces contextual equivalence in some form through the broader notion of relevance. This approach can account for the classical cases and, once combined with Meyer's (2013) approach to ignorance implicatures, it can also address the presupposed ignorance challenge in full, including the original cases by Spector and Sudo (2017) and the variants that we present below. As we will discuss, while Meyer's (2013) proposal is also compatible with competing approaches, the resulting systems still fail to achieve the same results. Finally, this approach captures some of the overgenerating cases mentioned above, while some other cases remain problematic for it as well. We end the paper with a synthetic comparison of the different approaches to MP and MP-like phenomena vis-a-vis the old and novel cases. All in all, the issue of how to properly restrict the competition for MP-like phenomena, accounting for the classical and the novel cases, remains an important challenge for all accounts in the literature.

\section{Background}

\subsection{The challenge to contextual equivalence}

A recent line of work has investigated cases like (4) and (5), which are often treated together with the classical ones above (a.o., Sharvit and Gajewski 2008; Gajewski and Sharvit 2012; Spector and Sudo 2017; Marty and Romoli 2021): ${ }^{1}$

\footnotetext{
${ }^{1}$ We note that, for some speakers, the naturalness of (5a) may improve if we change the topic of conversation and replace, for instance, the implicit question under discussion 'What colleges will Mary and Sue
} 
(4) Context: It is common ground between Bill and Olivia that all of the students passed. They are currently talking about their colleague John. One of them says:

a. \#John is unaware that some of the students passed.

b. John is unaware that all of the students passed.

(5) Context: Two Yale alumni are talking about what colleges their daughters will go to. One of them says that her daughter, Mary, will go to Yale. The other says:

a. \#Sue $F$, too, will go to Yale or MIT.

b. Sue $_{F}$, too, will go to Yale.

Given the similarities between (4)-(5) and the classical cases in (1)-(2), it is tempting to try and subsume the effects in (4)-(5) under MP as well. However, as Sharvit and Gajewski (2008) and Spector and Sudo (2017) discuss, cases like (4) and (5) are beyond the scope of application of MP: although the competing (b)-sentences carry stronger presuppositions which are met in context, they are not contextually equivalent to the (a)-sentences and therefore the third condition in (3c) is not met.

To account for these cases, Spector and Sudo (2017) (S\&S henceforth) extend the classical MP approach above by dropping the contextual equivalence requirement, and propose a system based on two distinct forms of scalar strengthening, which operate independently but interact with one another. First, they adopt a regular theory of scalar implicatures that operates at the assertion level and allows the presuppositions of the negated alternatives to project. Second, in place of MP, they propose the pragmatic principle in (6), a generalised version of MP, which they call the Presupposed Ignorance Principle (PIP henceforth).

(6) Presupposed Ignorance Principle (PIP, from Spector and Sudo 2017) A sentence $\phi$ is infelicitous in context $c$ if there is an alternative $\psi$ to $\phi$ such that:

a. $\quad \psi$ 's presupposition asymmetrically entails $\phi$ 's presupposition, and

b. $\psi$ 's presupposition is satisfied in $c$.

In short, the formulation of the PIP parallels that of MP up to one critical stage: the PIP leaves out the MP-requirement in (3c) that the presuppositional competitors to a given sentence be contextually equivalent to that sentence, allowing in principle more presuppositional competitors than MP. This minimal amendment allows S\& S to capture the cases in (4)-(5), where contextual equivalence does not obtain, while preserving the classical ones in (1)-(2). Finally, S\&S argues that the interaction between the PIP and the computation of scalar alternatives can account for contrasts like the one between (4a) and its positive counterpart in (7).

go to?' with a Yes-No question such as 'Will Marie and Sue go to college?'. In such contexts, as it seems, an utterance of (5a) can be understood as conveying that Sue will also go to college and that she will go to Yale or MIT - that is, as providing a positive answer to the Yes-No question at stake, while elaborating further on Sue's options. On this interpretation, (5a) can thus be paraphrased explicitly as 'Sue F too (will go to college): she will go to Yale or MIT'. While this interpretation of (5a) is certainly possible, it does not seem to be readily available to all speakers, and it is not the interpretation we are after. 
Context: It is common ground between Bill and Olivia that all of the students passed. They are currently talking about their colleague John. One of them says:

John is aware that some of the students passed.

Just like (4a), (7) has a presuppositionally stronger alternative whose presupposition is met in context, namely John is aware that all of the students passed. However, as we discuss in detail below, the meaning of (7), unlike that of (4a), can be strengthened by computing the scalar implicature associated with this alternative - that is, by negating this alternative and subsequently letting its presupposition project up. As a result, (7) together with its scalar implicature presupposes in fact that all of the students passed, and therefore the application of the PIP becomes vacuous in this case (i.e., there is no alternative with a stronger presupposition), hence the felicity of (7).

To illustrate in further detail, the system put forward by Spector and Sudo (2017) is based on the following ingredients: (i) the Presupposed Ignorance Principle (PIP) in (6), which operates at the presupposition level, (ii) a mechanism for computing implicatures at the assertion level, and (iii) the interaction between the mechanisms in (i) and (ii). At the presupposition level, the PIP essentially requires that among a set of alternative sentences, one should use the one(s) with the strongest presupposition(s) satisfied in context, regardless of whether it makes the same contribution in the context as the other alternatives (i.e., regardless of whether the considered alternatives are contextually equivalent). Consequently, whenever a sentence has an alternative with a logically stronger presupposition satisfied in context, the PIP predicts that sentence to be infelicitous. At the assertion level, scalar strengthening proceeds in standard ways. For concreteness, S\&S assume that scalar implicatures are computed by applying a covert exhaustivity operator, notated by 'EXH.' Adopting Fox's (2007) notion of Innocent Exclusion (IE) given in (8a), this operator can be defined as in (8b), where $\phi$ is any sentence and $\operatorname{ALT}(\phi)$ the set of formal alternatives to $\phi$. In short, applying EXH to a sentence $\phi$ outputs the conjunction of $\phi$ and the negation of all of $\phi$ 's alternatives that are innocently excludable, i.e., those alternatives to $\phi$ that can be consistently negated simultaneously without contradicting $\phi$ or entailing the truth of other alternatives.

$$
\begin{array}{ll}
\text { a. } & \operatorname{IE}(\phi, S):=\bigcap\left\{S^{\prime} \mid \begin{array}{l}
S^{\prime} \subseteq S \text { and } S^{\prime} \text { is a maximal subset of } S \\
\text { such that }\{\neg \psi: \psi \in S\} \cup\{\phi\} \text { is consistent }
\end{array}\right\} \\
\text { b. } \quad[[\operatorname{EXH} \phi]](w)=[[\phi]](w) \wedge \forall \psi \in \operatorname{IE}(\phi, \operatorname{ALT}(\phi))[\neg[[\psi]](w)]
\end{array}
$$

In addition, $\mathrm{S} \& \mathrm{~S}$ refine the scalar strengthening mechanism above to account for its interaction with presuppositions. Specifically, adopting a trivalent semantics for presuppositions, S\&S propose to adjust the bivalent definition of EXH in (8) to a trivalent setting so as to let EXH pass up the presuppositions of the alternatives it excludes, just like negation passes up the presuppositions of the sentence it negates. Excludable alternatives are thus negated in a strong sense: the negation of an alternative $\psi$ with presupposition $p$ is true if and only if $p$ is true and $\psi$ is false. In short, S\&S's adjustments are twofold: first, the notion of Innocent Exclusion in (8a) is redefined by making use of strong negation, and second, EXH is defined so as to behave as a 'presupposition hole' with respect to the presupposition of the alternatives. In other 
words, $[[\operatorname{EXH} \phi]](w)$ is undefined if any of its alternatives is undefined. The novel definition of EXH from Spector and Sudo $(2017,(63))$ is given in (9).

$$
\begin{aligned}
& {[[\operatorname{EXH} \phi]](w)} \\
& =\left\{\begin{array}{r}
\# \text { iff }[[\phi]](w)=\# \text { or for some } \psi \in \operatorname{IE}(\phi, \operatorname{ALT}(\phi)),[[\psi]](w)=\# \\
1 \text { iff }[[\phi]](w)=1 \text { and for all } \psi \in \operatorname{IE}(\phi, \operatorname{ALT}(\phi)),[[\psi]](w)=0 \\
0 \text { iff }[[\phi]](w)=0 \text { or for some } \psi \in \operatorname{IE}(\phi, \operatorname{ALT} \phi)),[[\psi]](w)=1 \\
\quad \text { and for no } \psi \in \operatorname{IE}(\phi, \operatorname{ALT}(\phi)),[[\psi]](w)=\#
\end{array}\right\}
\end{aligned}
$$

The PIP can be now more explicitly formulated as in (10), by taking into account the potential role of EXH. That is, a sentence $\phi$ is infelicitous if it has an alternative $\psi$, the presupposition of which is satisfied in the context and asymmetrically entails the presupposition of the strengthened meaning of $\phi$.

\section{Presupposed IGNORANCE PRINCIPLE (REFORMUlated)}

A sentence $\phi$ is infelicitous in a context $c$ if there is an alternative $\psi$ to $\phi$ such that:

a. $\psi$ 's presupposition asymmetrically entails $\operatorname{EXH}(\phi)$ 's presupposition, and

b. $\quad \psi$ 's presupposition is satisfied in $c$.

Given the assumptions about EXH, the PIP, and their interplay, the system by S\&S can account for the infelicity of cases like (4)-(5) and for the contrast between (4a) and (7), which are not covered by the classical MP approach. First, when (7) is strengthened by EXH, the presupposition of the negated all-alternative projects to the whole sentence. In other words, exhaustification strengthens the meaning of EXH's prejacent in two related ways: (i) by negating the assertion of its all-alternative, and subsequently (ii) by passing up the (stronger) presupposition of that alternative. As a result, the application of the PIP becomes vacuous, which accounts for the felicity of (7) in the relevant context.

EXH $\left[{ }_{\phi}\right.$ John is aware that some of the students passed $]$

$\operatorname{IE}(\phi, \operatorname{ALT}(\phi))=\{\mathrm{John}$ is aware that all of the students passed $\}$

a. ASR: John believes that some of the students passed, but it's not true that he believes that all of the students passed

b. PRS: All of the students passed

By contrast, in negative cases like (4a), the corresponding all-alternative is not excludable, and so exhaustification is vacuous and the PIP effectively applies, giving rise to a conflicting inference. That is, by application of the PIP, an utterance of (4a) triggers the presupposed ignorance inference $\neg \mathrm{CG}$ (all of the students passed). This makes the sentence contradictory with common ground, accounting for its infelicity.

(4a) \#EXH [ ${ }_{\phi}$ John is unaware that some of the students passed] $\operatorname{IE}(\phi, \operatorname{ALT}(\phi))=\{\}$

a. ASR: It's not true that John believes that some of the students passed

b. PRS: Some of the students passed

(4a) $\rightsquigarrow \neg \mathrm{CG}$ (all of the students passed) 
Through the PIP, S\&S's system can also account for the infelicity of (5a). Indeed, the sentence in (5a) has, among others, the formal alternatives in (11a) and (11b), each of which carries a stronger presupposition than the disjunctive presupposition of (5a). ${ }^{2}$ Thus, by application of the PIP, an utterance of (5a) is predicted to give rise to the inferences that neither the content of (11a)'s presupposition nor that of (11b)'s presupposition is common ground. As is easy to verify, the presupposed ignorance inference associated with (11a) conflicts with common ground since it was previously mentioned that Mary will go to Yale and therefore (11a)'s presupposition is satisfied in the suggested context.

$\mathrm{John}_{F}$, too, will go to Yale or MIT.

PRS: $\exists x[x \in c$ and $x \neq$ John and $x$ will go to Yale or MIT]
a. $\operatorname{John}_{F}$, too, will go to Yale.
PRS: $\exists x[x \in c$ and $x \neq$ John and $x$ will go to Yale $]$
b. $\operatorname{John}_{F}$, too, will go to MIT.
PRS: $\exists x[x \in c$ and $x \neq$ John and $x$ will go to MIT]

To summarise, Spector and Sudo (2017) propose two forms of scalar strengthening, operating at different levels and interacting with each other. At the assertion level, EXH negates the assertion of certain alternatives and passes up their presuppositions. At the presupposition level, the PIP derives weaker inferences about what is common ground. Importantly, the scope of application of the PIP can be tempered by the effect of exhaustification: scalar strengthening via EXH can sometimes 'rescue' a sentence from the infelicity that would otherwise arise from applying the PIP directly to the plain meaning of that sentence, like for instance in the analysis of (7) above. The interaction between these two scalar strengthening mechanisms is thus at the heart of S\&S's account of the asymmetry between (4a) and (7). This gives rise to the general prediction in (12).

\section{General prediction following from S\&S's system}

Let $S_{p}$ be any sentence with presupposition $p, S_{q}^{\prime}$ be an alternative to $S_{p}$ such that $q$ asymmetrically entails $p$, and $c$ be the utterance context of $S_{p}$. If $c$ entails $q$ and $\operatorname{EXH}\left(S_{p}\right)$ does not entail $q$, then $S_{p}$ is predicted to be infelicitous by the PIP.

The prediction in (12) holds because, in the absence of a bleeding relation between EXH and the PIP relative to the presupposition $q-$ a relation where $q$ does not end

\footnotetext{
${ }^{2}$ Here and throughout the paper, we assume that the additive particle too associates with a prosodically stressed element in the sentence - a focused constituent or contrastive topic - and that the interaction between the particle and this element determines the actual presupposition of the sentence (a.o., Rooth 1985, 1992; Krifka 1998; Saebo 2004). In our examples, the associate of too is the subject of the sentence and the presupposition is generated by replacing the subject with an existentially quantified individual variable that cannot take the referent of the subject as value. Following Heim (1990) and Kripke (2009), a.o., we also assume that the presupposition of too has an anaphoric component: its content must be salient enough in the context to be retrieved by the interlocutors. For the time being, we propose to implement this requirement by restricting the possible values of the existential quantifier to contextually salient individuals. Hence, a sentence like (5a) presupposes that some contextually salient individual other than John will go to Yale or MIT. The suggested context offers a suitable witness for this existential statement, namely Mary.
} 
up presupposed as a result of applying EXH - if $q$ is satisfied in $c$, then the PIP will generate the conflicting ignorance inference $\neg \mathrm{CG}(q)$, from which infelicity should follow. In the next subsection, we turn to the challenge to presupposition satisfaction and the proposal by Anvari (2018, 2019).

\subsection{The challenge to presupposition satisfaction}

Another challenge comes from the observation that MP-like effects may arise even though the stronger presupposition of the competing alternative is not satisfied in context, an observation originally from Percus 2010 and recently extended in Anvari 2018, 2019. This observation directly challenges another key ingredient of MP, the requirement that the presupposition of the competitor be satisfied in the context. To illustrate, consider the case in (13) from Percus 2010. While the two sentences at hand are contextually equivalent, the stronger presupposition of the (b)-sentence is not satisfied in the given context. Yet the (a)-sentence is intuitively infelicitous, which is not expected by MP or by the PIP.

Context: It is not established between the interlocutors whether their colleague, Mary, has any students this semester; but it is common ground that, as a rule, she takes two students on at a time, and so, if she has any at all, she has two. One of the interlocutors, who has recently talked to Mary, says:

a. \#Mary will bring all of her students.

b. Mary will bring both of her students.

On the basis of cases like (13), among others, Anvari (2019) proposes to replace MP with a different principle, which he dubs Logical Integrity (LI henceforth). In fact, LI is a generalisation which aims at capturing the unacceptability of a variety of sentences, some of which were previously captured by MP or the PIP. The gist of this generalisation is that a sentence $\phi$ is deemed infelicitous if it has an alternative $\psi$ that is logically non-weaker, yet contextually entailed by $\phi$. In other words, LI forces the logical relation between a sentence and its alternatives to be preserved once contextual information is considered, hence the name 'logical integrity'. We will consider the formulation of this principle in (14) and assume that a sentence is infelicitous if any part of it violates (14). ${ }^{3}$

LOGICAL INTEGRITY (LI, adapted from Anvari 2019, (5))

A sentence $\phi$ must not be uttered in a context $c$ if it has an alternative $\psi$ such that:

a. $\phi$ contextually entails $\psi$ in $c$, but

b. $\phi$ does not logically entail $\psi$.

Note that LI doesn't include the contextual equivalence ingredient of MP (replaced by contextual entailment), nor the requirement about presupposition satisfaction. As a result, LI can handle cases like (13), for it applies regardless of whether the presupposition of the competitor is satisfied in the context: (13a) is predicted to be infelicitous by LI because (13a) contextually entails (13b) but does not logically entail it.

\footnotetext{
${ }^{3}$ This is not the final version of the principle, which is associated with an additional 'projection principle' for local applications, but it is enough for our purposes; see Anvari 2019 for discussion.
} 
Moreover, as Anvari (2019) shows, LI can account for the classical MP cases and the asymmetry with factives. To illustrate, consider first the sentence in (1). The definite competitor to (1a) in (1b) is not logically entailed by (1b) (the former can be undefined when the latter is true). In the given context, however, if (1a) is true, then so is its definite-alternative. Hence, we have contextual but not logical entailment, and consequently (1a) violates LI in this context. Next, consider the contrast in (4): the all-alternative to (4a) in (4b) is not logically entailed by (4a), but when we add the assumed contextual information that all of the students passed, (4b) becomes contextually entailed by (4a). Thus, (4a) is correctly predicted to be infelicitous by LI. On the other hand, (7) is neither logically nor contextually entailed by its all-alternative in (15) and so, unlike (4a), (7) does not violate LI. Therefore, the contrast between (4a) and (7) is also nicely captured by this approach.

John is aware that all of the students passed.

It is worth noting, however, that unlike the PIP approach, the LI approach does not capture the contrast in (5), i.e., the presupposed ignorance case from $\mathrm{S} \& \mathrm{~S}$. The reason for that is that the formal alternatives to (5a) in (11) are neither logically nor contextually entailed by (5a), and therefore they do not qualify as competing alternatives to (5a) in light of LI. In the absence of such competitors, the infelicity of (5a) is left unexplained by LI.

\subsection{Summary}

Some of the key ingredients of MP have been challenged in the recent literature. The requirement of contextual equivalence has been challenged by cases like (4a), while that of presupposition satisfaction has been challenged by cases like (13). In response to the first challenge, Spector and Sudo (2017) have put forward a more general principle, the PIP. In response to the second challenge, Anvari (2019) has proposed that we replace MP with a novel principle, LI, which also weakens the requirement of contextual equivalence.

In the next section, we evaluate the empirical adequacy of the PIP and LI with respect to a set of novel cases. The results of this investigation are challenging for both approaches, and specifically for the idea that contextual equivalence can be harmlessly eliminated from the set of conditions restricting the set of presuppositional competitors to a given sentence. We will mostly focus on the requirement of contextual equivalence for now, but we will go back to presupposition satisfaction in Sect. 4. The cases to be discussed involve, among others, environments giving rise to existential presuppositions, cardinal partitives, the restrictor of universal quantifiers and the antecedent of conditionals, and a variant of S\&S's presupposed ignorance case. ${ }^{4}$

\section{Problems: Overgenerating and undergenerating infelicity}

This section presents in turn four cases which are problematic for both S\&S's and Anvari's proposals. In the first three cases, we will see that the PIP and LI overgenerate in

\footnotetext{
${ }^{4}$ Another challenge for both S\&S's and Anvari's proposals has been pointed out in the recent literature and pertains to the interaction between presuppositions and free choice disjunction through a phenomenon called Presupposed Free Choice; see Marty and Romoli 2021 for discussion.
} 
predicting infelicity for sentences which are intuitively felicitous; in the last one, we will see that they undergenerate by not predicting the infelicity of intuitively infelicitous sentences. But before going on, some methodological considerations are in order.

A simple way of testing the prediction of the PIP in (12) is to consider cases which do not involve exhaustification, given the general properties of the context or the properties of the linguistic environment in question. There are at least two ways to do that. First, we can consider the possible implicatures that a sentence may give rise to and verify that the presuppositions of those implicatures do not affect the subsequent application of the PIP. Second, we can rely on linguistic contexts that render the application of EXH vacuous in the first place. This can be done for instance by setting up the surrounding context so as to force implicature suspension, as in (16), or by embedding the relevant sentence in a downward-entailing (DE) environment (e.g., under negation), as in (17). Interestingly, conditionals combine both advantages: the antecedent of conditionals is a DE-environment (or at least non-UE) and conditionals give rise to an ignorance inference about their antecedent, as illustrated in (18) (a.o., Gazdar 1979).

\section{Suspension Test 1: Speaker's explicit ignorance}

I don't know whether all of the students passed, but some of them did.

$\rightsquigarrow$ The speaker doesn't know whether all of the students passed

\section{Suspension Test 2: Downward-entailing environments}

It is not the case that some of the students passed.

$\Varangle \rightarrow$ It is not the case that some but not all the students passed

\section{Combining Test $1 \&$ 2: Antecedent of conditionals}

If some of the students passed, then John is one of them.

a. $\quad \rightsquigarrow$ The speaker doesn't know whether some of the students passed (and therefore the speaker doesn't know whether all of them did)

b. $\quad \longleftrightarrow$ If some but not all the students passed, then John is one of them

We will use both these verification strategies whenever applicable to assess the possible effects of exhaustification and provide additional controls for our test cases.

\subsection{Case 1: Existential presuppositions}

Consider a sentence with a presuppositional predicate like (19). We can paraphrase the presupposition of this sentence as in (19a) and its asserted content as in (19b).

Jane didn't stop smoking.

a. PRS: Jane used to smoke

b. AsR: Jane smokes now

Consider now embedding stop in the scope of a quantifier, as in (20) and (21). Intuitively, while the presupposition of stop projects universally in the scope of all, it doesn't do so in the scope of existential quantifiers like those in (21)..$^{5}$

\footnotetext{
${ }^{5}$ See Chemla 2009 for experimental evidence that presuppositions do not project universally in existential quantifiers, and see also Sect. 6 for discussion.
} 
All of my students stopped smoking. $\rightsquigarrow$ All of my students used to smoke

(21) Some/At least one/Few/Less than three of my students stopped smoking. $\not \rightarrow$ All of my students used to smoke

In the following, we will use the quantifier and scalar item some and assume for simplicity that the presupposition of (21) is an existential presupposition, i.e., Some of my students used to smoke. We note, however, that all that is needed for creating the problem below is simply that the presupposition be weaker than universal. Against this background, consider again the sentence in (21), with its presupposition in (21a) and its asserted content in (21b). Importantly for our purposes, (21) can be felicitously uttered in a context in which it is known that all of my students used to smoke.

(21) Context: It is common ground that all of the speaker's students used to smoke.

Some of my students stopped smoking.

a. PRS: Some of my students used to smoke

b. ASR: These students don't smoke now

Note, however, that (21) has (22) as a presuppositionally stronger alternative, the presupposition of which is also satisfied in those contexts. If the PIP were to apply on the basis of the competition between (21) and (22), it would incorrectly predict (21) to be infelicitous.

(22) Context: It is common ground that all of the speaker's students used to smoke.

All of my students stopped smoking.

a. PRS: All of my students used to smoke

b. ASR: All of my students don't smoke now

S\&S's system, however, does not make this unwarranted prediction. Since (22) is also assertively stronger than (21), the meaning of (21) can be first strengthened by computing the implicature associated with (22), the presupposition of which then projects to the whole sentence, as shown in (23). This strengthening operation renders the application of the PIP vacuous, since (23) and (22) are now presuppositionally equivalent. As a result, the sentence in (21) is in fact expected to be felicitous in the context above on its strengthened meaning.

EXH [some of my students stopped smoking] $\Leftrightarrow$ some of my students stopped smoking but not all of them did

a. ASR: Some of my students stopped smoking, but not all of them did

b. PRS: All of my students used to smoke

This result is intuitively correct and, in fact, such cases could even be taken as an argument for S\&S's proposal regarding the interactions between EXH and the PIP. There is, however, an immediate expectation that follows from the general prediction 
in (12): in contexts in which (22)'s presupposition is satisfied but the 'rescuing' implicature in (23) gets suspended, the PIP should apply in a non-vacuous fashion, and therefore infelicity should follow. This expectation can be tested using the suspension tests outlined above.

Consider first a case like (24), where the speaker explicitly asserts that he is ignorant about the all-alternative in (22). This short discourse is felicitous, and the fact that it is tells us that, in that context, the implicature in (23) is suspended, for otherwise the continuation in (24) would give rise to a contextual contradiction. But precisely in the absence of this implicature, one would expect the PIP to apply and, therefore, the second sentence in (24) to be infelicitous, contrary to facts.

(24) Context: It is common ground that all of the speaker's students used to smoke.

I don't know whether all of them stopped. But (I know that) some of them did.

$\not \rightarrow$ Not all of my students stopped smoking

In response to (24), one could try to make use of a notion of relevance to explain why the stronger all-alternative is considered neither by EXH nor by the PIP in such cases. For instance, one could hypothesize that an alternative $\psi$ to a sentence $\phi$ cannot take part in any strengthening operation affecting $\phi$ 's meaning if the speaker is known to be ignorant about $\psi$. This explanation, however, does not extend to our second way of testing implicature suspension. Consider for instance the sentences in (25), where (21) and (22) are now embedded in the antecedent of conditionals: 6

Context: It is common ground that all of the speaker's students used to smoke.

a. If some of them stopped smoking, Jane will be happy.

b. If all of them stopped smoking, Jane will be happy.

Intuitively, (25a) conveys its plain (i.e., non-strengthened) meaning, compatible with that of (25b). And indeed, the computation of a not-all implicature in this environment is generally disfavoured as it would weaken (rather than strengthen) the global meaning of (25a). In the absence of an implicature, the PIP should thus apply on the basis of the competition between (25a) and (25b), predicting (25a) to be felic-

\footnotetext{
${ }^{6}$ The question of whether the antecedent of conditionals is a DE-environment is a debated one. What is important for us is that this environment is uncontroversially one in which scalar implicatures tend to disappear and out of which presuppositions tend to project. Thus, the most natural reading of a sentence like (25a), which is intended here, is one that leaves open the possibility that Jane will be happy if all of the speaker's students stopped smoking. For completeness, we note that the problem can be recreated with other, less controversial DE-environments, as in (i).
}

(i) Context: It is common ground that all of the speaker's students used to smoke.

I doubt that some/many of them stopped smoking. 
itous only if it is not common ground that all the students used to smoke. But this prediction is incorrect since (25a) is in fact felicitous in the context above. ${ }^{7,8}$

Note that it could be argued that EXH applies in (25a) nonetheless, precisely because its application is needed to rescue the sentence from infelicity. Yet this explanation faces two serious issues. First, it does not align with speakers' intuitions about the meaning of (25a): speakers accept (25a) as felicitous in the absence of the not-all implicature. Second, if we were to assume that EXH nonetheless applies in DE-environments like (25a), we would lose S\&S's explanation for the asymmetry between (4a) and (7), since EXH could then be applied in (4a) too, preventing the PIP from applying and thus rescuing that sentence from infelicity. ${ }^{9}$ Similar data can be reproduced with other presuppositional triggers (e.g., another, again, definite descriptions), and other downward entailing contexts. ${ }^{10}$

In sum, one crucial feature of S\&S's system is the interaction between EXH and the PIP, where the application of the former takes precedence and may lead to a vacuous application of the latter. The cases we just presented are problematic for this architecture because they are cases where EXH does not apply and the conditions of application of the PIP are met, and therefore they are incorrectly predicted to be infelicitous.

Turning now to the LI approach, it is easy to show that it encounters the same overgeneration issues as the PIP. To illustrate, consider again the case of existential presuppositions in (21). Anvari's proposal has no problem with this particular case, since the all-alternative in (20) is not contextually entailed by (21) even when we consider the contextual information that all of my students used to smoke. That is, in the relevant cases, (20) is neither logically nor contextually entailed by (21). However, if we move to the minimal variant of (21) in (25a), the situation changes: the all-alternative to (25a) in (25b) is not logically entailed by (25a), yet if we add the contextual information above, contextual entailment now obtains. Therefore, LI incorrectly predicts $(25 \mathrm{a})$ to be infelicitous. ${ }^{11}$

\footnotetext{
${ }^{7}$ Arguably, one also needs to make sure that it is possible in context that all of the speaker's students stopped smoking, as it is arguably another presupposition of the all-alternative in this environment. This requirement can easily be met by adding for instance the background information that recent anti-smoking campaigns have had significant impacts on students.

${ }^{8}$ We note that integrating Meyer's (2013) proposal into S\&S's system, as we discuss later in Sect. 5, would provide another solution to the case in (24). However, it would not provide a solution for the case in (25a). Thanks to Benjamin Spector for discussion on this point.

${ }^{9}$ Specifically, we could then analyse (4a) as in (i), where EXH occurs below negation.

(i) not $[\mathrm{EXH}[\phi \mathrm{John}$ is aware that some of the students passed] $]$

$\operatorname{IE}(\phi, \operatorname{ALT}(\phi))=\{\mathrm{John}$ is aware that all of the students passed $\}$

a. ASR: $\neg[$ John believes that some of the students passed and doesn't believe that all of them passed]

b. PRS: All of the students passed
}

${ }^{10}$ There might be discrepancies between presuppositional triggers in regard to projection in quantificational environments. In particular, some triggers have been argued to project universally from the scope of all quantifiers; see Charlow 2009, Romoli 2012, Chemla 2009 for discussion. Once again, our argument above holds only of those triggers for which there is less than universal projection.

${ }^{11}$ This argument holds if one assumes a semantics of conditionals which makes their antecedents downward monotonic. But the same argument can be reproduced with other, less controversial DE-environments (see footnote 6 above). 
In sum, LI replaces the notion of contextual equivalence with that of contextual entailment and, in so doing, it successfully covers the novel cases by S\&S discussed above. The examples in this subsection, however, are challenging for this proposal because, while the competitors are not contextually equivalent, the asserted sentences do contextually entail their competitors and are therefore incorrectly predicted to be infelicitous by LI.

\subsection{Case 2: Cardinal partitives}

Consider the sentences in (26), each of which involves the cardinal partitive phrase three of the lawyers that John hired associated with the existential presupposition that there are at least three individuals that are lawyers and that John hired.
a. Three of the lawyers that John hired just arrived.
PRS: There are (at least) three lawyers that John hired
b. Will three of the lawyers that John hired come to the trial?
PRS: There are (at least) three lawyers that John hired
c. If three of the lawyers that John hired have arrived, the trial can begin. PRS: There are (at least) three lawyers that John hired

It has long been observed that the use of cardinal partitives is subject to an antimaximality requirement (a.o., Jackendoff 1977; Hoeksema 1984; Barker 1998; Zamparelli 1998; Sauerland and Yatsushiro 2004, 2017; Marty 2017, 2019b). That is, the sentences in (26) can be felicitously used in a conversation only if it is not common ground that John hired exactly three lawyers. This observation can be further exemplified by the contrast in (27), adapted from Marty (2019b, (23)).
a. John hired exactly three lawyers, and \#[three of them/three of his lawyers] just arrived.
b. I can't remember how many lawyers in total John hired, but [three of them/three of his lawyers] just arrived.

In (27a), the speaker makes it common ground that John hired exactly three lawyers, and this prevents the subsequent use of the partitive phrase three of John's lawyers from being felicitous. By contrast, in (27b), the speaker is ignorant as to whether John hired exactly three or more lawyers, and the use of this same phrase is felicitous.

It has been proposed in Marty $(2017,2019 \mathrm{~b})$ that the anti-maximality condition on the use of those partitives follows from the general competition between indefinite phrases and their presuppositionally stronger definite alternatives, which has been traditionally subsumed under the scope of MP (cf. Heim 1991). In short, cardinal partitives like three of the lawyers that John hired are indefinite phrases headed by a silent indefinite determiner and compete with their definite cardinal variants, e.g. the three lawyers that John hired. Thus, a sentence like (26a) has the sentence in (28) as an alternative. This alternative carries a stronger presupposition but is equivalent, in its assertion part, to (26a) (i.e., in every context in which the presuppositions of (26a) and (28) are satisfied, the two sentences are equivalent). 
(28) The three lawyers that John hired just arrived

a. PRS: There are exactly three lawyers that John hired

b. ASR: These three lawyers just arrived

By MP, an utterance of (26a) is thus predicted to be felicitous only in contexts in which the presupposition of (28) is not satisfied, that is, if it is not common ground that John hired exactly three lawyers. It is worth noting here that MP does not impose any further requirement. In particular, note that the hypothetical alternatives to (26a) in (29), although similar in structure to (28) and presuppositionally stronger than (26a), are not contextually equivalent to (26a), and therefore they do not qualify as presuppositional competitors to (26a) in regard to MP.
a. The four lawyers that John hired just arrived
PRS: There are exactly four lawyers that John hired
b. The five lawyers that John hired just arrived
PRS: There are exactly five lawyers that John hired
c. The six lawyers that John hired just arrived
PRS: There are exactly six lawyers that John hired
d. etc...

The situation changes, however, if one adopts the PIP in place of MP here: if we are to eliminate the condition on contextual equivalence, then all the definite alternatives to (26a) above are now expected to compete with (26a). Applying the PIP to (26a) on the basis of these alternatives amounts to generating, for each of these alternatives, an ignorance inference targeting their presuppositional content (e.g., $\neg$ $\mathrm{CG}$ (exactly three) \& $\neg \mathrm{CG}($ exactly four) \& $\neg \mathrm{CG}$ (exactly five), etc.). Summing up these inferences gives rise in the end to the following prediction: (26a) should be felicitous only if (a) it is common ground that John hired at least three lawyers (i.e., the plain presupposition of (26a)), but (b) it is not common ground how many lawyers John exactly hired (i.e., by application of the PIP). This prediction is, however, incorrect, as (26a) is fully felicitous in a context where the number of lawyer hired by John is known by the interlocutors.

(26a) Context: It is common ground that John hired exactly four lawyers.

Three of the lawyers that John hired just arrived.

Could it be then that the application of the PIP is blocked here by the application of $\mathrm{EXH}$ ? In the above case, it would be so for instance if there was an innocently excludable alternative to (26a) against which the meaning of (26a) could be exhaustified so as to add the presupposition that John hired exactly four lawyers, blocking in effect the application of the PIP. As we will now see, however, there is no such alternative to fulfil this role.

Consider first the formal alternatives to (26a) in (29). Those definite alternatives are all logically stronger than (26a) and, taken independently, any of these alternatives can be negated consistently with the plain meaning (26a). For instance, negating the four-alternative to (26a) in (29a) would give rise to the implicature that the four lawyers that John hired didn't arrive, which would then add to (26a)'s presupposition the presupposition of interest, namely that John has exactly four lawyers. However, 
those alternatives cannot all be negated at the same time consistently with the plain meaning (26a) since the presuppositions associated with those alternatives are logically inconsistent with one another (i.e., John has exactly four lawyers, John has exactly five lawyers, John has exactly six lawyers, etc.). As a result, the definite alternatives to (26a) in (29) are not innocently excludable, and thus cannot be used to prompt scalar reasoning and block the application of the PIP.

Next, we note that sentences like (26a) also have indefinite cardinal alternatives such as (30), which are also logically stronger than them, both at the presupposition and at the assertion level:

(30) Four of the lawyers that John hired just arrived.

a. PRS: There are (at least) four lawyers that John hired

b. ASR: Four of them just arrived

Yet adding those alternatives to the picture does not solve the issue at hand. First, while exhaustifying the plain meaning of (26a) against the alternative in (30) would strengthen (26a)'s presupposition, as shown in (31), the representation resulting from this strengthening would still be presuppositionally weaker than the definite fouralternative in (29a), and therefore would not prevent the PIP from applying.

EXH $\left[{ }_{\phi}\right.$ three of the lawyers that John hired just arrived] $\operatorname{ALT}(\phi)=\{$ four of the lawyers that John hired just arrived $\}$

a. ASR: Three but not four of the lawyers that John hired just arrived

b. PRS: There are (at least) four lawyers that John hired

$\nRightarrow$ There are exactly four lawyers that John hired

Second, while we illustrated the point above with four for simplicity, sentences like (26a) have in fact infinitely many indefinite alternatives of that sort, all of which are innocently excludable (e.g., five of the lawyers that John hired just arrived, six of the lawyers that John hired just arrived, etc.). Thus, the reasoning in (31) should apply in principle to any numeral $n$ larger than three, in which case we would have EXH negating all alternatives of the form $n$ of the lawyers John hired arrived, for any $n$ larger than three. Adding the presupposition of each of those negated alternatives, i.e. John hired at least 4, 5, 6, 7, .. . lawyers, is now going to entail that John hired infinitely many lawyers; this entailment is certainly not an inference that people draw upon hearing sentences like (26a).

EXH $\left[{ }_{\phi}\right.$ three of the lawyers that John hired just arrived]

$\operatorname{IE}(\phi, \operatorname{ALT}(\phi))=\{n$ of the lawyers that John hired just arrived $\mid n>3\}$

a. ASR: Three but not $n$ of the lawyers that John hired just arrived, for any $n>3$

b. PRS: There are (at least $n$ ) lawyers that John hired, for any $n>3$

$\Rightarrow$ There are infinitely many lawyers that John hired

In light of our discussion, one may still wonder whether a solution for this problem in S\&S's system would not be to stipulate that numerals may only compete with their immediate 'neighbours'. On this view, the alternatives for 'three' would just be 'two' and 'four'. Another way to formulate that idea would be to state that the closer 
a numeral is to the one used in EXH's prejacent, the more likely it is to contribute to alternatives (we thank Benjamin Spector for pointing this possibility out to us). That assumption, prima facie, would indeed permit one to account, for instance, for the case in (26a) by singling out the potential role of the definite four-alternative in (29a): if we are to preserve only the 'two' and 'four' alternatives to 'three', then the four-alternative in (29a) would become innocently excludable and its exclusion would block the PIP successfully.

As it stands, however, the above stipulation would face serious issues beyond the mere absence of an independent motivation. First, it cannot account for variants of (29a) such as (33). In order for the PIP to be blocked by scalar reasoning, the domain of EXH would need here to include the definite alternative for 'ten', which is quite distant from 'three', and crucially to include only that definite alternative since, if other alternatives of the same sort were in EXH's domain (e.g., all alternatives up to 'ten'), then that alternative would no longer be innocently excludable.

Context: It is common ground that John hired exactly ten lawyers.

Three of the lawyers that John hired just arrived.

Second, the problem for Spector and Sudo (2017) would re-emerge in DE-environments. As before, embedding (26a) in a DE-environment as in (26c) does not change the picture: a sentence like (26c) can be felicitously used if it is common ground that John hired exactly $n$ lawyers, for any $n>3$. Crucially, note that, as expected, the natural reading of (26c) does not have an embedded implicature; (26c) does not suggest that if three but not four/five/six/etc. of the lawyers that John hired arrived, the trial can begin.

(26c) Context: It is common ground that John hired exactly four lawyers.

If three of the lawyers that John hired have arrived, the trial can begin.

The same observations hold for LI. The felicity of (26a) is unproblematic for LI since the definite alternatives in (29) are neither logically nor contextually entailed by (26a) in the given context. Yet the variant of (26a) in (26c) recreates the same problem for LI as above: (26c) does not logically entail the definite four-alternative in (34), but it does contextually entail it in contexts in which it is common ground that John hired exactly four lawyers. (26c) is therefore predicted to be infelicitous by LI, contra speakers' intuitions.

If the four lawyers that John hired arrived, the trial can begin.

We now turn to a third set of overgenerating cases, which involve the restrictor of universal quantifiers and the restrictor of which-phrases, and the antecedent of conditionals.

\subsection{Case 3: Restrictors}

A common assumption in the literature is that universally quantified sentences like (35), or definite descriptions like (36), require that their restrictor be non-empty. That is, (35) and (36) presuppose that there is at least one individual who is a student and came to class (see Heim and Kratzer 1998, Ch. 6, and references therein). 
(35) All of the students who came to class understood the puzzle.

PRS: Some students came to class

(36) The students who came to class understood the puzzle.

PRS: Some students came to class

Consider now the variant in (37), which contains a disjunction in the restrictor of all/the: ${ }^{12}$

Context: It is common ground that some students met with either Danny or Irene, others with both.

All/The students who met with Danny or Irene understood the puzzle.

PRS: Some students met with Danny or Irene

(37) has the alternative in (38), which is assertively weaker and presuppositionally non-weaker than (37). Thus, according to the PIP, (37) should be felicitous only in contexts where the presupposition of (38) is not satisfied, that is, where it is not common ground that some student(s) met with both Danny and Irene. Yet this prediction is not borne out: as evidenced above, (37) is in fact felicitous in such contexts. Crucially, note that exhaustification cannot help in this case either: EXH is vacuous if applied globally (i.e., at root level), and it would lead to an intuitively wrong meaning if applied locally (i.e., in the restrictor of all/the).

(38) Context: It is common ground that some students met with either Danny or Irene, others with both.

All/The students who met with Danny and Irene understood the puzzle.

PRS: Some students met with Danny and Irene

Similar data can be reproduced with the antecedent of conditionals, as shown in (39). ${ }^{13}$ Thus for instance, (39a) has the alternative in (39b) which, in a way similar as above, is assertively weaker but presuppositionally stronger than (39a). Contra the predictions of the PIP, however, (39a) can be felicitously uttered in a context where (39b)'s stronger presupposition is met.

(39) Context: It is common ground that it is possible that Jane met with both Danny and Irene.

a. If Jane met with Danny or Irene, she understood the puzzle. PRS: It is possible that Jane met with Danny or Irene

b. If Jane met with Danny and Irene, she understood the puzzle. PRS: It is possible that Jane met with Danny and Irene

\footnotetext{
${ }^{12}$ Spector and Sudo (2017, Sect. 6.1) discuss similar cases as an open problem for their account and point to a proposal by Sudo (2016), involving analogous cases with implicatures, as a possible solution. It is unclear to us whether that proposal can extend to our cases here. We thank Benjamin Spector and Yasu Sudo for discussion on this point.

${ }^{13} \mathrm{As}$ before, we assume that a sentence like (39a) is preferentially understood as conveying its nonstrengthened reading, which is compatible with that of (39b) (see footnote 6 for discussion). This reading can be further encouraged by making it common ground that the more professors a student met with, the more likely it is that she understood the puzzle.
} 
And the very same problem arises with the restrictor of which-phrases:

(40) Context: It is common ground that some students met with either Danny or Irene, others with both.

a. Mary knows which students met with Danny or Irene.

PRS: Some students met with Danny or Irene

b. Mary knows which students met Danny and Irene.

PRS: Some students met with Danny and Irene

One could hope to address the issues above by restricting the scope of application of the PIP, for instance by restricting its application to alternatives whose assertive content is not entailed by the assertion of the base sentence, as suggested in (41).

\section{Presupposed IGNORANCE PRINCIPLE (MOdified)}

A sentence $\phi$ is infelicitous in a context $c$ if there is an alternative $\psi$ to $\phi$ such that:

a. $\quad \psi$ 's presupposition asymmetrically entails $\phi$ 's presupposition, and

b. $\psi$ 's presupposition is satisfied in $c$, and

c. $\psi$ 's assertion is not entailed by $\phi$ 's assertion.

The additional restriction in (41c) would take care of the universal quantifier cases above and, under certain assumptions about the semantics of conditionals and embedded questions, it might extend to those cases as well. However, the restrictor of the definite determiner the is a non-monotonic context and so, in contrast to the other cases, the presuppositionally stronger alternative is not entailed; in those cases, the same issue would thus arise even on the modified version of the PIP in (41). Similar data can be reproduced with other non-monotonic contexts, like the restrictor of most, as exemplified in (42). Here again, the problem is that the presuppositionally stronger alternative to (42a) in (42b) is not entailed by (42a), and so the issue re-emerges.

Context: It is common ground that some students met with either Danny or Irene, others with both.

a. Most students who met with Danny or Irene understood the puzzle.

PRS: Some students met with Danny or Irene

b. Most students who met with Danny and Irene understood the puzzle.

PRS: Some students met with Danny and Irene

For similar reasons, LI makes incorrect predictions for these cases as well. This is because, in the given context, the sentences in (37), (39a), (40a), and (42a) contextually entail their and-alternatives, but do not logically entail them (i.e., these alternatives can be undefined given their presuppositions). Therefore, they are predicted to be infelicitous by LI; once again, this prediction is incorrect.

\subsection{Case 4: Speaker-oriented ignorance}

Our fourth and last set of cases shows that, when it comes to presupposed ignorance, S\&S's and Anvari's proposals also face undergeneration issues. As a starting point, 
consider the example in (5a), which corresponds to the second case motivating S\&S's departure from contextual equivalence in favour of the PIP.

(5a) Context: Two Yale alumni are talking about what colleges their daughters will go to. One of them says that her daughter, Mary, will go to Yale. The other says:

\#Sue $_{F}$, too, will go to Yale or MIT.

a. ASR: Sue will go to Yale or MIT

b. PRS: $\exists x[x \in c$ and $x \neq$ Sue and $x$ will go to Yale or MIT]

As we discussed, the infelicity of (5a) is left unexplained by MP or LI while it is accounted for by the PIP. The reason for that is that, unlike MP or LI, the PIP allows (5b) to be a presuppositional competitor to (5a). Hence, (5a) is expected to give rise through the PIP to the presupposed ignorance inference that it is not common ground that some contextually salient individual other than Sue, namely Mary, will go to Yale. This inference contradicts the common ground, since the interlocutors know that Mary will go to Yale, accounting for the infelicity of (5a).

(5b) Sue $_{F}$, too, will go to Yale.

a. AsR: Sue will go to Yale

b. PRS: $\exists x[x \in c$ and $x \neq$ Sue and $x$ will go to Yale $]$

However, Marty and Romoli (2021) observe that the PIP fails to account for minimally different versions of (5a), which also involve disjunctive presuppositions. To illustrate, consider first the example in (43), which offers a different instance of the same problem:

Context: It is common ground between Bill and John that Olivia only took Logic, and they are discussing what classes their advisor, Noah, thinks she took. Bill says:

\#Noah is unaware that Olivia took Logic or Algebra.

(cf. Noah is unaware that Olivia took Logic)

The observation here is simply that (43) cannot be felicitously uttered in a context in which it is established between the interlocutors that Olivia took Logic (or, alternatively, that Olivia took Algebra). It is easy to see that the PIP can account for this observation through the exact same reasoning as before: an utterance of (43) is infelicitous in the suggested context because, by application of the PIP, it gives rise to two inferences, $\neg \mathrm{CG}$ (Olivia took Logic) and $\neg \mathrm{CG}$ (Olivia took Algebra), one of which contradicts the common ground. Yet as Marty and Romoli (2021) argue, the explanatory challenge surrounding presupposed ignorance is more general. Specifically, they observe that similar infelicity effects reproduce in cases like (44), even though neither of the embedded disjuncts are common ground among the interlocutors. Thus for instance, in run-of-the-mill contexts, (44a) is infelicitous even if it is not common ground whether the speaker has children. ${ }^{14}$

\footnotetext{
${ }^{14}$ In order to become acceptable, the sentences in (44) and (45), must each speak to a highly specific point, which requires an explicit yes-no context or a quasi-quotational use of the disjunctive phrase. To illustrate,
} 
(44) a. \#Noah is unaware that I have a son or a daughter.

b. \#Sue didn't realise that my wife was born in France or in Japan.

c. \#Mary was sorry that Sue had lunch with Noah or me yesterday.

The infelicity effects at hand in these examples are in fact similar to those previously observed for their non-embedded, non-presuppositional variants in (45) (a.o., Gazdar 1979; Fox 2007; Singh 2008, 2010; Fox and Katzir 2011).
a. \#I have a son or a daughter.
b. \#My wife was born in France or in Japan.
c. \#Sue had lunch with Noah or me yesterday.

Taken at face value, all these examples appear to be infelicitous because they give rise to speaker-oriented ignorance inferences that stand in contradiction with common assumptions about what any speaker should know generally. That is, a sentence like (44a), just like its unembedded variant in (45a), sounds odd because it conveys that the speaker herself is ignorant about the gender of her child, and this piece of information conflicts with the common assumption that people are normally knowledgeable about such personal facts. ${ }^{15}$ The problem, however, is that the PIP is not designed to mandatorily generate such speaker-oriented ignorance inferences. In fact, the PIP only generates for (44a) the inference that the gender of the speaker's child is not common ground; the issue is that this inference is and remains compatible with the common ground as long as this information is not mutually shared by the interlocutors (e.g., if this information is not known to the speaker's addressee). In sum, Spector and Sudo's (2017) proposal only offers a partial solution to the empirical challenge of presupposed ignorance: it accounts for the infelicity effects in (5a) but leaves those of the variants in (44) unexplained. ${ }^{16}$

For completeness, we note that, for similar reasons, LI does not capture our variants of (5a) in (44): in a context in which it is not known whether the speaker has a son or a daughter, the formal alternatives to (44a) in (46) are neither logically nor contextually entailed by (44a). Hence, the LI approach does not account for the infelicity effects in (44) either.

suppose, for instance, that having a son or a daughter puts you into a different and more advantageous tax bracket, compared to having no children. In this context, you may felicitously utter (45a) to confirm your taxpayer status. Similarly, if Noah is your accountant, you may felicitously utter (44a) to express that Noah lacks certain pieces of personal information that are relevant for filling out your tax form and that he could be mistaken about the tax bracket you're in. The relevance-based approach that we will put forward will account for the acceptability of these particular examples: in such contexts, no ignorance implicature is drawn from (45a) or (44a), because neither of the disjuncts (i.e., I have a son, I have a daughter) is independently relevant given the question under discussion.

${ }^{15}$ Of course, this common assumption need not hold in all contexts. For instance, in amnesia-like contexts, it can be assumed instead that the speaker has forgotten such personal information. And indeed, in such contexts, all of the examples above become felicitous.

${ }^{16}$ As Marty and Romoli (2021) discuss, this issue would disappear if some additional mechanism could be postulated so as to force the outcome of the PIP to be narrowed down from common ground to the speaker's epistemic state, for then the conflicting speaker-oriented inferences that we described would obtain. We refer the readers to Marty and Romoli (2021) for a critical discussion of this idea and related analytical options and why it appears non-trivial to integrate them with S\&S's system in order to account for the infelicity effects at hand. 
(46) a. Noah is unaware that I have a son.

b. Noah is unaware that I have a daughter.

\subsection{Intermediate summary}

We have presented several problematic cases for S\&S's and Anvari's proposals. In the first three cases, we showed that both the PIP and LI overgenerate in predicting infelicity for felicitous sentences. In the fourth and last case, we showed that they also undergenerate by not capturing the infelicity of infelicitous sentences carrying disjunctive presuppositions. These findings leave us with the following dilemma at this point. On the one hand, none of the overgeneration cases that we discussed (Cases 1-3) are problematic for MP, for none of them involves a competition between contextually equivalent alternatives; but the scope of application of MP is too restrictive to capture S\&S's and Anvari's novel cases and our variants above, including Case 4. On the other hand, the PIP and LI generalise MP by dropping or weakening the condition on contextual equivalence and successfully account for the asymmetry with factives unveiled by S\&S; but their broader scope of application now leads to systematic overgeneration issues in Cases 1-3 above while, at the same time, undergenerating in Case 4, just like MP.

As a possible way out of this dilemma, we turn in the next sections to an alternative approach to MP, which proposes to broaden its scope of application while maintaining relatively strict conditions on competing alternatives. This approach is the implicature-based approach stemming from Magri 2009 and further developed in Marty 2017, 2019b, which, among other things, extends the application of EXH to presuppositional competitors and subsumes the condition on contextual equivalence under the broader notion of relevance. As we explain below, that condition is further extended to the presuppositional level in the version in Marty 2019b and Marty and Romoli 2021. This approach also aims at capturing a broad class of unacceptable sentences, starting with the classical MP-cases. For space reasons, however, we will evaluate its empirical coverage only with regard to the target cases discussed in this paper: classical MP cases like (47), the PIP-motivating examples from S\&S in (48) and (49) (which we call the 'asymmetry' and 'presupposed common ignorance' cases, respectively, for convenience), and our four new cases in (50)-(53).

\section{Classical MP cases}

Context: It is common ground that John has two parents.

a. \#All of John's parents left.

b. Both of John's parents left.

\section{Asymmetry}

Context: It is common ground between Bill and Olivia that all of the students passed. They are currently talking about their colleague John. One of them says:

a. \#John is unaware that some of the students passed.

b. John is aware that some of the students passed. 
(49) Presupposed common ignorance

Context: Two Yale alumni are talking about what colleges their daughters will go to. One of them says that her daughter, Mary, will go to Yale. The other says:

\#Sue, too, will go to Yale or MIT.

(50) Presupposed speaker's ignorance

Context: The gender of the speaker's child is not common ground. \#Noah is unaware that I have a son or a daughter.

\section{Existential presuppositions}

Context: It is common ground that all of the speaker's students used to smoke.

a. Some of my students stopped smoking.

b. If some of my students stopped smoking, Jane will be happy.

(52) Cardinal partitives

Context: It is common ground that John hired exactly four lawyers.

a. Three of the lawyers that John hired just arrived.

b. If three of the lawyers that John hired arrived, the trial can begin.

(53) Restrictors

Context: It is common ground that some students met with both Danny and Irene, and that Jane is possibly one of them.

a. All/Most/The students who met with Danny or Irene understood the puzzle.

b. If Jane met with Danny or Irene, she understood the puzzle.

The remainder of the paper is structured as follows. Section 4 introduces the implicature-based approach. By reintegrating the notion of contextual equivalence in some form, this approach can deal with one of our novel cases (the case of cardinal partitives in (52)), in addition to the classical MP ones and the asymmetry with factives; however, the cases in (51) and (53) still remain problematic for this approach, which is also insufficient by itself to account for the presupposed ignorance cases in (49)-(50). In Sect. 5, we show however that this latter limitation can be overcome: once we consider the grammatical approach to ignorance implicatures from Meyer 2013, the implicature-based approach offers a satisfying solution to the presupposed ignorance challenge (see also Marty and Romoli 2021). As we discuss, while Meyer's (2013) proposal is also compatible with the PIP and LI, the resulting systems are unable to address the presupposed ignorance challenge in its full generality.

\section{Moving to relevance}

We will start by outlining the implicature-based approach to MP effects, building on Magri (2009) and Marty (2017, 2019b). We will refer to this approach as the M\&M system. This system integrates contextual equivalence within a notion of relevance, allowing it to account for the classical MP-cases in the same way as the original MP approach, and further applies that notion of relevance at the presupposition level. 
The resulting approach accounts for the asymmetry in (48) as well as for the case of cardinal partitives in (52). Yet the existential presuppositions and restrictor cases will be shown to remain problematic for this approach as well.

\subsection{The proposal in brief}

On the theory of implicatures developed in Magri 2009, 2011, 2013, the infelicity of a sentence like (54) is hypothesized to result from the mandatory computation of a mismatching implicature, that is, an obligatory implicature which contradicts the common ground.

\#Some Italians come from a beautiful country.

a. Parse: $\operatorname{EXH}_{\mathcal{R}}\left[{ }_{\phi}\right.$ some Italians come from a beautiful country]

b. Alternative: [ $\psi$ all Italians come from a beautiful country]

c. Relevance: $\quad \psi \Leftrightarrow \Leftrightarrow_{c} \phi$ and so $\psi \in \mathcal{R}$

d. Obligatory implicature: \#Not all Italians come from a beautiful country

The gist of Magri's theory is that a sentence like (54) must be parsed with an exhaustivity operator, (54a). Just like any other quantifier, the domain of this operator is taken to be restricted by a contextually assigned relevance predicate $\mathcal{R}$; the exhaustivity operator with its restriction is written ' $\mathrm{EXH}_{\mathcal{R}}$ '. The denotation of $\mathcal{R}$ is assigned by the context of EXH's prejacent and thus varies across contexts, accounting for the context-dependency of implicatures, i.e., for the possibility of suspending an implicature in certain contexts but also for the impossibility of doing so in others. ${ }^{17}$ In particular, since relevance is assumed to be closed under contextual equivalence, if the prejacent $\phi$ of $\operatorname{ExH}_{\mathcal{R}}$ in (54a) is relevant, then so is its all-alternative $\psi$ in (54b), since $\psi$ and $\phi$ are contextually equivalent relative to $\phi$ 's context (corresponding here to the global context $c$ ). As a result, the implicature associated with $\psi$ becomes mandatory in this case, resulting in a representation that contradicts the common ground (i.e., $\left.c \cap \operatorname{EXH}_{\mathcal{R}}(\phi)=c \cap(\phi \wedge \neg \psi)=\emptyset\right)$. In addition to relevance considerations, the domain of quantification of EXH is also regulated by general economy considerations (a.o., Fox and Spector 2009; Magri 2011; Spector and Sudo 2017; Fox and Spector 2018): since the computation of an implicature must lead to meaning strengthening, an alternative that can be pruned from the domain of EXH must effectively be pruned if the implicature associated with that alternative would weaken or leave unaffected the global meaning of the sentence.

\footnotetext{
${ }^{17}$ We assume that relevance is modelled using questions under discussion (QUDs, see Roberts 2004; Beaver and Clark 2009 among many others). Assume that the QUD is associated with a partition of the context set, which corresponds to the set of complete answers to this question (a.o., Heim 1994; Groenendijk et al. 1984; Groenendijk and Stokhof 1984; Bennett 1979). The notion of relevance can then be defined as in (i), where $Q$ is the partition associated with the QUD: a proposition is relevant if and only if it does not distinguish between two worlds within a cell of $Q$.

(i) Let $Q$ be a partition of the context set. A proposition $p$ is relevant given $Q$ iff for any cell $q \in Q$ and any two worlds $w, w^{\prime} \in q, p(w)=p\left(w^{\prime}\right)$.

It follows from (i) that, if a proposition $p$ is entailed by the context set (e.g., if $p$ is a presupposition satisfied in the context), then, for any partition $Q$ of that context set, $p$ cannot distinguish between the worlds within any cells of $Q$, and therefore $p$ is relevant.
} 
Building on Magri's insights, Marty (2017) proposes to extend this theory to presuppositional effects. ${ }^{18}$ In essence, Marty (2017) argues that, when computing the implicatures of a sentence $\phi$, speakers entertain two sets of alternatives that are mutually exclusive and distinguished on the basis of Strawson-entailment: (i) a set of presuppositional alternatives, comprising the formal alternatives to $\phi$ that can only be undefined when $\phi$ is true (i.e., those alternatives that are Strawson-entailed), as in (55a) below, and (ii) a set of assertive alternatives, comprising the formal alternatives to $\phi$ that can be false when $\phi$ is true (i.e., those alternatives that are not Strawson-entailed), as in (56a). ${ }^{19}$ As Marty (2017) discusses, on this proposal, we need exclusion to be performed innocently on both sets of alternatives. For presuppositional alternatives, we adopt the procedure of innocent exclusion (IE ${ }^{\text {prs }}$ ) proposed in Marty (2017), shown in (55b), which applies Fox's (2007) notion to the presuppositional domain. For assertive alternatives, we follow Marty and Romoli (2021) in assuming that innocent exclusion ( $\mathrm{IE}^{a s r}$ ) is computed as shown in (56b), by taking all maximal sets of assertive alternatives that can be negated consistently with the prejacent and the negation of the presupposition of all IE ${ }^{\text {prs }}$ alternatives. This second definition slightly departs from Marty (2017) in that $\mathrm{IE}^{a s r}$ is computed on the basis of $\mathrm{IE}^{\text {prs }}$ rather than independently.

\section{Excludable and innocently excludable presuppositional alternatives}
a. $\mathrm{E}^{p r s}(\phi)=\{\psi: \psi \in \operatorname{ALT}(\phi) \& \phi \not \models \psi \& \phi, p s p(\psi) \models \psi\}$
b. $\quad \operatorname{IE}^{\text {prs }}(\phi, S):=\bigcap\left\{\begin{array}{l|l}S^{\prime} & \begin{array}{l}S^{\prime} \subseteq S \text { and } S^{\prime} \text { is a maximal subset of } S \text { such } \\ \text { that }\{\neg p s p(\psi): \psi \in S\} \cup\{\phi\} \text { is consistent }\end{array}\end{array}\right\}$

\section{Excludable and innocently excludable assertive alternatives}

$\begin{array}{ll}\text { a. } & \left.\operatorname{E}^{a s r}(\phi)=\{\psi: \psi \in \operatorname{ALT}(\phi) \& \phi, p s p(\psi) \not \psi\}\right\} \\ \text { b. } & \operatorname{IE}^{a s r}(\phi, S):= \\ & \bigcap\left\{\begin{array}{ll}S^{\prime \prime} \mid \begin{array}{l}S^{\prime \prime} \subseteq S \text { and } S^{\prime \prime} \text { is a maximal subset of } S \text { such that } \\ \neg \psi \psi \psi \\ \text { consistent }\end{array}\end{array}\right\}\end{array}$

Following this characterisation of assertive and presuppositional alternatives, Marty (2017) proposes that the exhaustivity operator be defined as in (57).

\footnotetext{
${ }^{18}$ Marty (2017) implements this theory in a uni-dimensional approach to meaning, using partial semantics for presuppositions. The core theory is then integrated into a dynamic theory of interpretation, using a notion of local contexts along the lines of Karttunen (1974) and Heim (1983).

${ }^{19}$ As Spector and Sudo (2017) discuss, once we move to a trivalent or partial semantics, there are various ways to define the notions of entailment and consistency. We assume here that entailment is defined as in (i), i.e., as 'strict entailment', and that consistency is defined as in (ii).

(i) $\quad \phi$ entails $\psi$ iff, for any world at which $\phi$ is true, $\psi$ is also true at that world.

(ii) A set of propositions $S$ is consistent iff all of its members can be true at the same world.

Finally, we assume that the negation used in the definitions of this subsection is so-called 'strong' negation (see Spector and Sudo 2017 for discussion). That is, $\neg \phi$ is defined only if $\phi$ is defined (i.e., $p \operatorname{sp}(\phi)$ is true) and, where defined, $\neg \phi$ is true iff $\phi$ is false.
} 


\section{Exhaustivity operator for assertive and presuppositional alternatives}

a. $\quad\left[\mathrm{EXH}_{\mathcal{R}} \phi\right]$ is defined at a world $w$ only if

(i) $\operatorname{psp}(\phi)$ is true in $w$, and

(ii) for all $\psi$ s.t. $\psi \in \mathrm{IE}^{a s r}\left(\phi, \mathrm{E}^{a s r}(\phi)\right)$ and $\psi \in \mathcal{R}$, $p \operatorname{sp}(\psi)$ is true in $w$, and

(iii) for all $\psi$ s.t. $\psi \in \operatorname{IE}^{p r s}\left(\phi, \mathrm{E}^{p r s}(\phi)\right)$ and $p \operatorname{sp}(\psi) \in \mathcal{R}, \neg p s p(\psi)$ is true in $w$

b. Where defined, $\left[\mathrm{EXH}_{\mathcal{R}} \phi\right]$ is true in $w$ iff

(i) $\phi$ is true in $w$, and

(ii) for all $\psi$ s.t. $\psi \in \operatorname{IE}^{a s r}\left(\phi, \mathrm{E}^{a s r}(\phi)\right)$ and $\psi \in \mathcal{R}, \neg \psi$ is true in $w$

In this framework, applying EXH to a sentence $\phi$ can strengthen $\phi$ 's presupposition in one of two ways. ${ }^{20}$ First, in a way similar to Spector and Sudo's (2017) proposal, presupposition strengthening can happen indirectly upon projection of the presupposition of $\mathrm{IE}^{a s r}$ alternatives: $\mathrm{EXH}_{\mathcal{R}}$ passes up to the whole sentence the presuppositions of the negated IE ${ }^{a s r}$ alternatives to the prejacent, as shown in (57a). Second, presupposition strengthening can happen as a direct result of an implicature: here too, EXH passes up to the whole sentence the negation of the relevant presuppositions of the IE ${ }^{\text {prs }}$ alternatives to its prejacent, as in (57a).

Finally, M\&M's system inherits from Magri's original system the idea that EXH's domain is modulated both by relevance and economy considerations. In particular, with respect to relevance, if the prejacent $\phi$ of EXH is relevant, then any assertive alternative to $\phi$ that is contextually equivalent to $\phi$ is also relevant (Magri 2009, 2011). Conversely, if $\phi$ is not relevant to begin with, then $\operatorname{EXH}(\phi)$ is infelicitous. This logic is extended in Marty 2019b and Marty and Romoli 2021 to presuppositional alternatives by assuming that, for those alternatives, speakers assess relevance by considering the relevance of their presuppositional contribution. ${ }^{21}$ For our immediate purposes, it is enough to observe that, given the way the notion of relevance is usually defined in the literature, if a proposition is entailed by the context, then that proposition trivially counts as relevant. As a result, if the prejacent $\phi$ of EXH is assertable in a context $c$ (i.e., if $c$ entails $\phi$ 's presupposition), then $\phi$ 's presupposition is relevant in $c$ and so are the presuppositions of $\phi$ 's presuppositional alternatives that are contextually equivalent to $\phi$ 's presupposition. Conversely, if $\phi$ is not assertable to begin with, e.g., $\phi$ 's presupposition isn't met prior to utterance and fails to be accommodated, then $\operatorname{EXH}(\phi)$ is infelicitous. Crucially, if an assertive alternative or the presupposition of a presuppositional alternative is deemed relevant in that sense, it cannot be pruned from $\mathcal{R}$ and thus from the domain of EXH; consequently, any assertive or presuppositional implicature associated with such an alternative is predicted in M\&M's system to be mandatory.

\footnotetext{
${ }^{20}$ In works like Magri (2011) and Marty (2017), it is assumed that an occurrence of EXH must be present at every propositional node. For our purposes, however, we only need to assume that EXH is mandatory at matrix level, since we will not be concerned here with infelicity effects arising from the computation of conflicting embedded implicatures. We refer the reader to Marty (2017) for discussion and refinements of this assumption in the case of presupposed implicatures.

${ }^{21}$ We refer the reader to Marty $(2019 \mathrm{~b}, 4.3-4.4)$ for an explanation and a discussion of the pragmatic rationale underlying the formulation of this extended requirement.
} 


\subsection{Good predictions}

First, M\&M's system readily accounts for the classical MP effects. To illustrate, consider the sentence in (47a), which is parsed with an occurrence of the exhaustivity operator at matrix level, as shown below. The presuppositional both-alternative to EXH's prejacent is innocently excludable and, since its presupposition is satisfied in the suggested context, its presupposition counts as relevant and thus must be excluded. In a way similar to what we saw in (54), the mandatory computation of this implicature results in a contextually contradictory representation; infelicity follows. ${ }^{22}$

(47a) Context: It is common ground that John has only two parents.

\#All of John's parents left.
a. Parse: $\mathrm{EXH}_{\mathcal{R}}[\phi$ all of John's parents left]
b. IE ${ }^{\text {prs }}$ : $[\psi$ both of John's parents left $]$
c. Relevance: $\quad c \subseteq p s p(\psi)$ and so $\operatorname{psp}(\psi) \in \mathcal{R}$
d. Obligatory implicature: \#John doesn't have exactly two parents

On certain assumptions, M\&M's system can also account for variants such as (13), repeated below, which have been pointed out as a challenge to presupposition satisfaction:

Context: It is not established between the interlocutors whether their colleague, Mary, has any students this semester; but it is common ground that, as a rule, she takes two students on at a time, and so, if she has any at all, she has two. One of the interlocutors, who has recently talked to Mary, says:

a. \#Mary will bring all of her students.

b. Mary will bring both of her students.

In fact, a solution to this challenge preserving the original formulation of MP has already been put forward in Marty 2019a. This solution starts from the observation that, in order for (13a) to be felicitous, two requirements must be met: (i) for the informative presupposition of (13a) to be satisfied, the context must be adjusted so

\footnotetext{
${ }^{22}$ Anvari (2019) argues that, contrary to MP, M\&M's system generates certain inferences that are stronger than attested. For instance, in M\&M's system, a sentence like (i) has the potential to give rise to a global presuppositional implicature, i.e. not every professor has exactly two students, but also to a local presuppositional implicature which, upon projection under every, gives rise to the stronger presupposition that every professor has more than two students. Yet as Anvari (2019) observes, speakers generally accept sentences like (i) in contexts where it is known that some professors have exactly two students, i.e., in contexts where the local implicature is false.

(i) Every professor ${ }_{i}$ invited all his p $_{i}$ students.

Parse: $\operatorname{EXH}_{\mathcal{R}}$ [every professor $\lambda x \operatorname{EXH}_{\mathcal{R}}[x$ invited all $x$ 's students] $]$

a. Global: $\neg$ [for every professor $x, x$ has exactly two students]

b. Local: for every professor $x, \neg[x$ has exactly two students $]$

This observation is discussed in Marty (2017, Ch. 2) and it is shown to be unproblematic for M\&M's system: as long as the presupposition of the both-alternative is not satisfied in its local context, the local implicature in (ib) can be suspended, independently of the global one, simply by pruning the both-alternative from the domain of the embedded EXH, hence ensuring felicity in the kind of contexts considered by Anvari (2019).
} 
as to entail that Mary has students (e.g., by presupposition accommodation), and (ii) for MP to be obeyed, the local context to which (13a) is added should not entail (13b)'s stronger presupposition that Mary has exactly two students. As Marty 2019a observes, however, these felicity conditions cannot be met altogether in cases like (13): if (i) is met, then it follows that (ii) isn't, and so infelicity ensues by MP; alternatively, if (ii) is met, then it follows that (i) isn't, and so infelicity ensues due to presupposition failure. This solution can easily be integrated with M\& M's system as well as with the PIP. Thus for instance, on this solution, (13a) is predicted to be infelicitous in M\&M's system because either (13a)'s presupposition is accommodated, in which case the presupposition of (13b) is relevant in the context of evaluation and a mismatching presuppositional implicature arises, or else (13a)'s presupposition fails to be accommodated, in which case (13a) suffers from presupposition failure.

Second, M\&M's system offers a simple solution to the issue raised by cardinal partitives: of all the definite alternatives to indefinite partitives of the form ' $n$ of the NPs', only the one of the form 'the $n$ NPs' qualifies as a presuppositional alternative by the definition given in (55). All other definite alternatives qualify instead as assertive alternatives and are not innocently excludable since negating them all upon exhaustification would project presuppositions that are mutually inconsistent (e.g., John has exactly 4 and exactly 5 lawyers). Consequently, in a way similar to MP, M\&M's system correctly predicts (52a) and (52b) to be infelicitous only in those contexts in which John is known to have hired exactly 3 lawyers, i.e., in contexts in which the presupposition of their definite three-alternative is satisfied.

(52a) $\operatorname{EXH}_{\mathcal{R}}\left[{ }_{\phi}\right.$ three of the lawyers that John hired just arrived]

a. $\quad\{$ the three lawyers that John hired just arrived $\} \subseteq \operatorname{IE}\left(\phi, \mathrm{E}^{\text {prs }}(\phi)\right)$

b. $\{$ the four/five/etc. lawyers that John hired just arrived $\} \nsubseteq \operatorname{IE}\left(\phi, \mathrm{E}^{\text {prs }}(\phi)\right)$

c. $\left\{\right.$ the four/five/etc. lawyers that John hired just arrived $\left\{\nsubseteq \mathrm{IE}\left(\phi, \mathrm{E}^{a s r}(\phi)\right)\right.$

Finally, the M\&M approach accounts for the asymmetry with factives from Spector and Sudo (2017). Consider again the contrast in (48), repeated below for convenience:

Context: It is common ground between Bill and Olivia that all of the students passed. They are currently talking about their colleague John. One of them says:

a. \#John is unaware that some of the students passed.

b. John is aware that some of the students passed.

In M\&M's system, this contrast stems from the different status of the target allalternatives in both cases. In (48a), the target all-alternative is a presuppositional alternative to EXH's prejacent: upon exhaustification, the negation of its (stronger) presupposition can be added to the plain presupposition of EXH's prejacent. In the present case, since the presupposition of the presuppositional all-alternative to EXH's prejacent is satisfied, this strengthening is mandatory and results in a contextual contradiction, hence the infelicity of (48a). 
(48a) \#John is unaware that some of the students passed.

a. Parse: $\operatorname{EXH}_{\mathcal{R}}$ [ $\phi$ John is unaware that some of the students passed]

b. IE ${ }^{\text {prs }}$ [ $\quad[\psi$ John is unaware that all of the students passed $]$

c. Relevance: $\quad c \subseteq p \operatorname{sp}(\psi)$ and so $p \operatorname{sp}(\psi) \in \mathcal{R}$

d. Obligatory implicature: \#Not all the students passed

In (48b), by contrast, the corresponding all-alternative is an assertive alternative to EXH's prejacent: upon exhaustification, its presupposition and the negation of its (stronger) assertion can be added to the plain meaning of EXH's prejacent. Note that, in the absence of contextual equivalence, this strengthening process is predicted to remain optional.

(48b) John is aware that some of the students passed.

a. Parse: $\mathrm{EXH}_{\mathcal{R}}\left[{ }_{\phi}\right.$ John is aware that some of the students passed]

b. IE ${ }^{\text {asr }}$ [ $\quad[\psi$ John is aware that all of the students passed $]$

c. Relevance: $\quad \psi \oiint_{c} \phi$ and so pruning $\psi$ from $\mathcal{R}$ is possible

d. Possible implicature: John is not aware that all the students passed

M\&M's account of the contrast in (48) is therefore similar to Spector and Sudo's (2017). In particular, both accounts predict the sentence in (48a) to be odd due to the mandatory generation of some conflicting inference (attributed to the working of the PIP in one case, and to the working of EXH in the other), while no such conflict need to arise in (48b).

In closing, we note that the two accounts nonetheless make different predictions regarding two issues surrounding the felicity conditions of (48b). The first issue has to do with focus sensitivity: $S \& S$ argue that, in a context in which it is common ground that all of the students passed, the scalar term some needs to be stressed in order for (48b) to be felicitous. That is, while (58a) is felicitous in such contexts, (58b) isn't:

a. John is aware that SOME of the students passed.

b. \#John is aware that some of the students passed.

On S\&S's approach, this contrast follows if one assumes that prosodic prominence on the scalar term strongly correlates with the presence of EXH. In (58a), since some is stressed, scalar strengthening happens and the sentence is predicted to be felicitous. In (58b), by contrast, some isn't stressed and, in the absence of scalar strengthening, the sentence is predicted to be infelicitous through the PIP. On M\&M's approach, on the other hand, the implicature is predicted to remain optional in this case, given the absence of contextual equivalence with the target assertive alternative. This approach can thus account for the fact that stress on some, signalling the active work of EXH, is the most natural choice in the given context. It can also account for why (58b) is felicitous in a context in which it is not common ground that all of the students smoke. However, it does not readily account for the robust infelicity of (58b). The contrast in (58) seems therefore to favour S\&S's approach.

The second issue also pertains to the obligatoriness vs. optionality of the implicature associated with (48b). This time, however, it is the M\&M approach which appears to make the right prediction. In particular, Spector and Sudo's (2017) account predicts that, in order for (48b) to be felicitous in the context at hand, an implicature 
must be computed to avoid the PIP from generating a contextual contradiction. By contrast, M\&M's account predicts (48b) to be felicitous in that same context independently from such a strengthening process. With this in mind, consider the example in (59):

Context: It is common ground between Bill and Olivia that all of the students passed. They are currently talking about their colleague John. One of them says:

I really don't know whether John is aware that all the students passed. But he is aware that some of them did $(=(48 b))$.

$\leftrightarrow \rightarrow$ John is not aware that all the students passed

As before, the context at hand is one in which it is common ground that all of the students passed. However, the speaker is now explicitly stating that he is ignorant as to whether John is aware that all the students passed, and this information subsequently leads one to suspend the implicature previously associated with (48b). Crucially, we observe here that the suspension of that implicature leaves the felicity of (48b) unaffected. This is directly in line with M\&M's predictions but problematic at first sight for Spector and Sudo (2017): in the absence of the target implicature, the PIP should apply just like in (48a), and therefore the discourse in (59) should be perceived as infelicitous, contra speakers' intuitions. ${ }^{23}$

In sum, the two issues above have to do with the obligatoriness vs. optionality of the implicature associated with sentences like (48b), in a context in which the presupposition of the alternative is or is not satisfied. The first issue suggests a strong correlation between the presence of focus, the generation of the target implicature, and the felicity of (48b), while the second reveals that (48b) can be felicitous also in the absence of that implicature. S\&S's approach easily accounts for the former but not the latter issue, while M\&M's approach easily accounts for the latter but not the former.

\subsection{Presupposed ignorance unexplained}

Without further assumptions, the $\mathrm{M} \& \mathrm{M}$ approach cannot account for the presupposed ignorance cases in (49)-(50). To illustrate, consider the example in (49), which is parsed on this approach as shown in (60): of all the excludable assertive alternatives

\footnotetext{
${ }^{23}$ We note right away that integrating Meyer's (2013) proposal into S\&S's system, as we discuss below in Sect. 5, can provide a solution to this problem. Specifically, if we integrate Meyer's (2013) Matrix K Axiom into S\&S's system (see Sect. 5 for details), the second sentence in (59) (i.e., (48b)) could be parsed as shown in (ia), and EXH's prejacent would then have the formal alternative in (ib), the presupposition of which is made common ground in (59) by means of the first sentence.

(i) a. $\quad \operatorname{EXH}\left[{ }_{\phi} K_{S}\right.$ [John is aware that some of them passed]]

b. $\quad\left[\psi K_{S}[\mathrm{John}\right.$ is aware that all of them passed] $]$

Crucially, on this enriched theory, the unwarranted prediction we pointed out can be circumvented by computing for (ia) the implicature associated with (ib), i.e., that the speaker doesn't know whether John is aware that all of them passed. In passing up to the whole sentence its presupposition, that implicature can block the PIP from applying effectively, solving the issue at hand. In fact, this case could be taken as independent evidence that S\&S's system needs to be supplemented with a theory along the lines of Meyer's (2013) to counteract some unwarranted effects of the PIP.
} 
to (49), only the two conjunctive alternatives qualify as innocently excludable alternatives. Neither of those assertive alternatives is contextually equivalent to their base disjunctive sentence and, more to the point, neither of the implicatures associated with those alternatives has the potential to give rise to a contextual contradiction.

$\mathrm{EXH}_{\mathcal{R}}\left[{ }_{\phi} \mathrm{Sue}_{F}\right.$, too, will go to Yale or MIT]

a. $E^{a s r}(\phi)=\{[$ Sue will go to Yale], [Sue will go to MIT], [Sue will go to Yale and MIT], [Sue $F$, too, will go to Yale], [Sue $F$, too, will go to MIT], [Sue $F$, too, will go to Yale and MIT] $\}$

b. $\operatorname{IE}^{a s r}\left(\phi, \mathrm{E}^{\text {asr }}(\phi)\right)=\{[$ Sue will go to Yale and MIT], [Sue $F$, too, will go to Yale and MIT]\}

Similar observations hold of the speaker-oriented variant in (50), as illustrated in (61): of the three excludable presuppositional alternatives to (50), only the (presupposition of the) conjunctive one is innocently excludable. The resulting presupposed implicature (i.e., that the speaker doesn't have both a son and a daughter) is not in conflict with the common ground and cannot, therefore, account for the infelicity of (50).

$\operatorname{EXH}_{\mathcal{R}}\left[{ }_{\phi}\right.$ Noah is unaware that I have a son or a daughter]

a. $E^{\text {prs }}(\phi)=\{[$ Noah is unaware that I have a son], [Noah is unaware that I have a daughter], [Noah is unaware that I have a son and a daughter]\}

b. $\operatorname{IE}^{\text {prs }}\left(\phi, \mathrm{E}^{\text {prs }}(\phi)\right)=\{[$ Noah is unaware that $\mathrm{I}$ have a son and a daughter]\}

For now, the presupposed ignorance cases constitute a challenge for M\& M's system, which is not equipped to operate on scalar alternatives involving independent disjuncts. We will see in Sect. 5 that this limitation can yet be overcome by combining M\&M's system with Meyer's (2013) grammatical approach to ignorance implicatures.

\subsection{Remaining overgeneration problems}

While M\&M's system can account for the case of cardinal partitives, it encounters similar overgeneration issues as the PIP and LI for the other two cases. Consider first the case of existential presuppositions, repeated from above:

(51) Context: It is common ground that all of the speaker's students used to smoke.

a. Some of my students stopped smoking.

b. If some of my students stopped smoking, Jane will be happy.

Like the other two approaches, M\&M's system can readily account for the felicity of (51a): the all-alternative to (51a) in (62) is an assertive alternative to (51a), and that alternative is not contextually equivalent to (51a). As a result, the meaning of (51a) may but need not be exhaustified on the basis of (62): (51a) is correctly predicted to be felicitous either way.

All of my students stopped smoking. 
However, the minimal variant of (51a) in (51b) is problematic for this approach as well. To understand why, consider the all-alternative to (51b) in (63). First, we verify that (63) is logically non-weaker, yet Strawson-entailed by (51b); therefore, it counts in M\&M's system as a presuppositional alternative to (51b). Second, the presupposition of (63) (i.e., all of my students used to smoke) and that of (51b) (i.e., some of my students used to smoke) are satisfied in the suggested context; therefore, the computation of the presupposed implicature associated with (63) is predicted to be mandatory. ${ }^{24}$ Since the resulting implicature (i.e., not all of my students used to smoke) conflicts with the context, M\&M's system predicts (51b) to be infelicitous, which is incorrect.

If all of my students stopped smoking, Jane will be happy.

A similar problem arises when we move to the case of restrictors:

Context: It is common ground that some students met with both Danny and Irene, and that Jane is possibly one of them.

a. All/Most/The students who met with Danny or Irene understood the puzzle.

b. If Jane met with Danny or Irene, she understood the puzzle.

Consider the alternatives to (53a) and (53b) in (64a) and (64b), respectively. In M\&M's system, those alternatives count as presuppositional alternatives and, moreover, their presuppositions are satisfied in the context at hand. As a result, the presupposed implicatures associated with those alternatives are predicted to be obligatory and, since those implicatures conflict with the contextual assumptions, both (53a) and (53b) are incorrectly predicted to be infelicitous.

a. All/Most/The students who met with Danny and Irene understood the puzzle.

b. If Jane met with Danny and Irene, she understood the puzzle.

To summarise, M\&M's approach can account for the original MP cases, for the factive asymmetry from Spector and Sudo (2017), as well as for the case of cardinal partitives. However, it leaves presupposed ignorance unaccounted for at this point, and it faces the same problems as the PIP and LI with existential presuppositions and restrictors. While the first issue can be remedied by enriching M\&M's approach, as we shall now see, the latter will remain a problem.

\section{Extension to presupposed ignorance}

In this section, we go back to the various challenges posed by presupposed ignorance, by investigating in more detail the common and speaker-oriented ignorance cases as

\footnotetext{
${ }^{24}$ To be precise, the presuppositions of $(51 \mathrm{~b})$ should also include that it is possible that some of the speaker's students stopped smoking, which would also have to be satisfied in the context. We leave that presupposition aside since it is orthogonal to the argument we are making here.
} 
well as further variants. We show that a unified solution to all of these cases can be given by integrating Meyer's (2013) grammatical view on ignorance implicatures with the M\&M approach. As we discuss, while Meyer's (2013) proposal is also compatible with the PIP and LI, the resulting systems are unable to account for all the cases of presupposed ignorance as they stand.

\subsection{The challenge in more detail}

Consider first the case in (65), which illustrates what we have referred to as presupposed common ignorance (e.g., (49)):

\footnotetext{
Presupposed common ignorance

Context: Two people are talking about what foreign languages Mary and John, among others, know. One of them says that Mary speaks French. The other says:

\#John $_{F}$, too, speaks French or Japanese.
}

As we discussed, of all the approaches we considered, only the approach by S\&S can account for the infelicity of such sentences. However, just like the other approaches, it fails to account for the speaker-oriented variant of (65) in (66).

\section{Presupposed speaker's ignorance}

Context: It is not common ground which foreign language(s) the speaker knows.

\#Noah is unaware that I speak French or Japanese.

In this subsection, we add the observation that the $S \& S$ approach also runs into problems with minimally different versions of (65). Consider for instance the following two variants, which are to be read in a general context similar to the one in (65): ${ }^{25}$

\footnotetext{
a. Variant 1: Non-split conjunctive antecedent Context: Mary speaks French and Japanese. \#John $_{F}$, too, speaks French or Japanese.

b. Variant 2: Split conjunctive antecedent Context: Mary speaks (only) French and Bill speaks (only) Japanese. $\mathrm{John}_{F}$, too, speaks French or Japanese.
}

As S\&S themselves discuss, their approach does not capture the infelicity effect in (67a) in that it predicts (67a) to be infelicitous under certain parses, but not others.

\footnotetext{
${ }^{25}$ Uli Sauerland pointed out to us another interesting variant of (65):

(i) Mary, Bill, and Sue each speak French or Japanese. John $F$, too, speaks French or Japanese.
}

The first sentence is understood as conveying that each of three individuals speaks French or Japanese, and that at least one of them speaks French and at least one of them speaks Japanese. The local context of the second sentence is thus one in which, in a way similar to (67b), it is common ground that some individual other than John speaks French and that some other individual, also distinct from John, speaks Japanese. Thus, the PIP predicts here that the second sentence should be infelicitous because the alternatives $J o h n_{F}$ too speaks French and John $F$ too speaks Japanese both have stronger presuppositions that are met in context. If this analysis of (i) is on the right track, then (i) is also an issue for S\&S's approach. 
Specifically, if (67a) is parsed without any occurrence of EXH, it is predicted to be infelicitous by the PIP because the alternatives (i) John $n_{F}$, too, speaks French and Japanese, (ii) John $n_{F}$, too, speaks (only) French, and (iii) John $n_{F}$, too, speaks (only) Japanese all have stronger additive presuppositions that are met in context. Similarly, if (67a) is parsed with an occurrence of EXH taking scope below too, as in (68), the predicted presupposition is that there is a salient $x$ other than John such that $x$ speaks French or Japanese, but not both. As one can verify, this presupposition is false in the suggested context since the only salient $x$ is Mary and, by assumption, she is known to speak both languages.

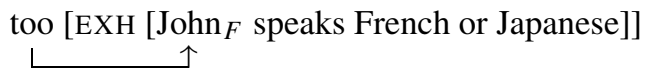

The problem is that there is also a possible parse for (67a), namely (69), under which the sentence is predicted to implicate that John speaks one language or the other but not both, while presupposing that there is some salient $x$ other than John which speaks both (i.e., the presupposition of the negated alternative $J o h n_{F}$, too, speaks French and Japanese). Since this presupposition is also satisfied in the suggested context, (67a) is incorrectly predicted to be felicitous under this parse (see Spector and Sudo 2017, Sect. 6.4).

\section{EXH [too [John $F$ speaks French or Japanese]] ᄂ}

The variant in (67b) raises another non-trivial issue for $S \& S$, because their approach incorrectly predicts (67b) to be infelicitous, on all relevant parses. First, if (67b) is parsed without any occurrence of EXH, it is predicted by the PIP to be infelicitous for the same reasons as above. Next, if we assume the parse in (69), then the predicted presupposition is, as before, that someone other than John speaks both languages; this time, however, this presupposition is false in the given context, since neither Mary nor Bill speaks both languages. Finally, if we assume the parse in (68), the predicted presupposition is that somebody other than John speaks French or Japanese, but not both. This presupposition is satisfied in the context, no matter whether this somebody is understood to be Mary or Bill. However, regardless of the choice of the antecedent, (67b) has on this parse certain alternatives whose presuppositions are logically stronger and are satisfied in the context. Thus for instance, the alternative in (70) presupposes that some salient individual other than John has the property of speaking only French, a property that Mary is known to have in the given context. Therefore, the PIP shall apply in this case, incorrectly predicting the sentence in (67b) to be infelicitous. ${ }^{26}$

\footnotetext{
${ }^{26}$ Benjamin Spector suggested to us that (67b) may not be problematic for S\&S if one assumes that the plural individual Mary and Bill is a possible witness for the existential presupposition of too. In that case, the presupposition of the second sentence would become that the plurality Mary and Bill speaks French or Japanese and that presupposition is satisfied in the context. Moreover, the presupposition of the alternatives $J o h n_{F}$, too, speaks French and John $n_{F}$, too, speaks Japanese would now be that the plurality Mary and Bill speaks French and that the plurality Mary and Bill speaks Japanese, respectively. Since those presuppositions are not satisfied, the PIP would not apply and, consequently, the sentence would be predicted to be felicitous. In sum, under the assumption that a context like (67b) is sufficient to make the
} 


$$
\text { too }\left[\mathrm { EXH } \left[\mathrm{John}_{F}\right.\right. \text { speaks French]] }
$$

In sum, S\&S's approach accounts for the basic case in (65), but it fails to extend to its speaker-oriented variants and to account for its variants in (67a) and (67b), by incorrectly predicting the former to be felicitous and the latter to be infelicitous (at least under certain assumptions; see fn. 26 for discussion). In light of those data, in the following we propose an alternative account of (65) and of its variants that extends a proposal by Meyer (2013) and integrates it with the M\&M approach.

\subsection{An exhaustivity-based solution}

\subsubsection{A grammatical epistemic layer}

One common way to account for ignorance inferences is to conceive them as implicatures derived from additional Gricean principles (a.o., Gazdar 1979; Sauerland 2004; Fox 2007, 2016). Meyer (2013) proposes instead that ignorance inferences are derived in the grammar through the interaction of the exhaustivity operator with another covert operator representing the speaker's beliefs (see also Meyer 2014; Buccola and Haida 2019). At the core of Meyer's proposal is the assumption - called the Matrix K Axiom - that assertively used sentences contain a covert doxastic operator $\mathrm{K}$, which is adjoined at the matrix level at LF (cf. Chierchia 2006; Alonso-Ovalle and Menéndez-Benito 2010). Much like the attitude verb believe, the Matrix K operator universally quantifies over the speaker's doxastic alternatives, as shown in (71). The subscript $x$ refers to the doxastic source, i.e., the individual whose beliefs $\mathrm{K}$ is quantifying over. In the cases that we will be concerned with, $x$ will always be the speaker, hence the notation $K_{s}{ }^{27}$

$$
\left[\left[K_{x} \phi\right]\right]=\lambda w . \forall w^{\prime} \in \operatorname{Dox}(x)(w)\left[[[\phi]]\left(w^{\prime}\right)\right]
$$

Meyer shows that the Matrix K Axiom, together with the possible adjunction of EXH at any propositional node (i.e., below and above K), derives speaker-oriented ignorance inferences. To illustrate, consider the simple disjunctive sentence in

(72) John speaks French or Japanese.

a. Exclusivity implicature:

$\rightsquigarrow$ The speaker believes that John doesn't speak French and Japanese

b. Ignorance inferences:

$\rightsquigarrow$ The speaker is ignorant about whether John speaks French

$\rightsquigarrow$ The speaker is ignorant about whether John speaks Japanese

plurality of the two mentioned individuals salient, the split conjunctive antecedent case is not problematic for $S \& S$.

${ }^{27}$ Here and throughout this paper, we will use $K$ in the meta-language to abbreviate the denotation of the Matrix K operator; i.e., we adopt the following convention: [[ $\left.\left.K_{x} \phi\right]\right]$ iff $K_{x} \phi$. 
Sentences like (72) are typically understood as conveying that (a) the speaker believes that John doesn't speak both French or Japanese, and (b) the speaker is ignorant about whether John speaks French and about whether John speaks Japanese. The inference in (a) corresponds to the genuine exclusivity implicature arising from the basic competition between disjunction and conjunction. The inferences in (b) are called ignorance inferences and are generally derived on the basis of the competition between the whole disjunction and its independent disjuncts: a disjunction ' $\phi \vee \psi$ ' generates speaker-oriented ignorance inferences about $\phi$ and about $\psi$ (e.g., Gazdar 1979). As Meyer shows, the pattern of inferences in (72) can be derived on her proposal with the parse given in (73). ${ }^{28,29}$

$\left[\mathrm{EXH}_{(1)}\left[K_{S}\left[\mathrm{EXH}_{(2)}[\mathrm{John}\right.\right.\right.$ speaks French or Japanese $\left.\left.]\right]\right]$

a. Exhaustification below $\mathrm{K}$

(i) $\mathrm{IE}^{\text {asr }}=\{[\mathrm{F}$ and $\mathrm{J}]\}$

(ii) Implicature: $\neg[\mathrm{F}$ and $\mathrm{J}]$

b. Exhaustification above $\mathrm{K}$

(i) $\mathrm{IE}^{a s r}=\left\{\begin{array}{c}{\left[\mathrm{K}_{s} \mathrm{EXH}_{(2)} \mathrm{F}\right],\left[\mathrm{K}_{s} \mathrm{EXH}_{(2)} \mathrm{J}\right],\left[\mathrm{K}_{s} \mathrm{EXH}_{(2)} \mathrm{F} \text { and J], }\right.} \\ {\left[\mathrm{K}_{s} \mathrm{~F}\right],\left[\mathrm{K}_{s} \mathrm{~J}\right],\left[\mathrm{K}_{s} \mathrm{~F} \text { and J] }\right.}\end{array}\right\}$

(ii) Implicatures: $\neg \mathrm{K}_{s}[\mathrm{~F} \wedge \neg \mathrm{J}], \neg \mathrm{K}_{s}[\mathrm{~J} \wedge \neg \mathrm{F}], \neg \mathrm{K}_{s}[\mathrm{~F}$ and $\mathrm{J}], \neg \mathrm{K}_{s}[\mathrm{~F}]$, $\neg \mathrm{K}_{s}[\mathrm{~J}]$

c. Exhaustification outcome

[EXH(1) $\left[K_{s}\left[\mathrm{EXH}_{(2)}[\mathrm{John}\right.\right.$ speaks French or Japanese]]]]

$\Leftrightarrow \mathrm{K}_{s}[\mathrm{~F}$ or $\mathrm{J}] \wedge \mathrm{K}_{s} \neg[\mathrm{F}$ and $\mathrm{J}] \wedge \neg \mathrm{K}_{s}[\mathrm{~F}] \wedge \neg \mathrm{K}_{s}[\neg \mathrm{F}] \wedge \neg \mathrm{K}_{s}[\mathrm{~J}] \wedge \neg \mathrm{K}_{s}[\neg \mathrm{J}]$

$\Leftrightarrow \mathrm{K}_{s}[\mathrm{~F}$ or $\mathrm{J}] \wedge \mathrm{K}_{s} \neg[\mathrm{F}$ and $\mathrm{J}] \wedge \mathrm{I}_{s}[\mathrm{~F}] \wedge \mathrm{I}_{s}[\mathrm{~J}]$

On the parse in (73), exhaustification is performed at two distinct levels, below $\mathrm{K}$ and above $\mathrm{K}$. Exhaustification below $\mathrm{K}$ gives us the classic not-and implicature: this implicature obtains as usual by negating the conjunctive alternative to $\mathrm{EXH}_{(2}$ 's prejacent, which is the only innocently excludable alternative at that level of the structure. Exhaustification above $\mathrm{K}$ now gives us the speaker-oriented ignorance inferences we were interested in: these ignorance inferences obtain by computing the implicatures associated with the formal alternatives to $\mathrm{EXH}_{(1)}$ 's prejacent, which correspond roughly to its independent disjuncts (with and without $\mathrm{EXH}_{(2)}$ ), all of which are innocently excludable. The resulting outcome, (73c), delivers the pattern of inferences we were after, (72).

As Marty and Romoli (2021) show, integrating Meyer's (2013) proposal into M\&M's system predicts the implicatures in (73b) and, consequently, the ignorance inferences following from them to be mandatory in certain contexts. The reason is that, in M\&M's system, the only way an implicature can be avoided is if the alternative it is based on can be pruned from the set of relevant propositions $\mathcal{R}$. Disjunctive

\footnotetext{
${ }^{28}$ For simplicity, we use $F$ and $J$ as short forms for the sentences John speaks French and John speaks Japanese, respectively. As is customary, we write $I_{s}(\phi)$ for 'the speaker $s$ is ignorant about $\phi$ ', where $I_{S}(\phi)$ holds if and only if both $\neg K_{S}(\phi)$ and $\neg K_{S}(\neg \phi)$ hold.

${ }^{29}$ Following Meyer (2013), we assume that the matrix K operator is immune from deletion: if a sentence includes $\mathrm{K}$, then $\mathrm{K}$ is preserved in the formal alternatives to that sentence. We do not assume, however, that this immunity applies to the (embedded) occurrences of EXH, which can be deleted as usual by substitution with a subconstituent (for a different view, see Meyer 2013).
} 
sentences are well known to be subject to additional discourse conditions. In particular, it is generally the case that for a disjunction to be felicitous its disjuncts have to be understood as relevant alternatives (Simons 2001; see also Fox 2007; Singh 2008; Fox and Katzir 2011; Marty and Romoli 2021 for discussion). In other words, as a rule of thumb, whenever a disjunction is relevant, so are its disjuncts (i.e., neither of the disjuncts can be pruned from $\mathcal{R}$ if the whole disjunction is itself in $\mathcal{R}$ ). ${ }^{30} \mathrm{We}$ adopt this line of explanation to account for the general observation that disjunctions give rise to ignorance inferences in ordinary conversations, and in particular for the observation that examples like those in (45) are infelicitous in run-of-the-mill contexts.

a. \#I have a son or a daughter.

b. \#My wife was born in France or in Japan.

c. \#Sue had lunch with Noah or me yesterday.

It is worth emphasising, however, that the description above is but a rule of thumb, one that aims at capturing speakers' interpretive preference (or bias) in run-of-themill contexts. As such, this rule of thumb need not be applied in more specific circumstances (see fn.30 for discussion and fn.14 for examples). Specifically, on the present approach, the sentences in (45) are predicted to be acceptable if, instead, the context of utterance makes it so that neither of the independent disjuncts is immediately relevant to the topic of conversation, thus suspending the ignorance implicatures that would otherwise be drawn from them. As shown in (74), this prediction is indeed borne out: a sentence like (45a) becomes felicitous in a context where all it matters to know is whether or not the speaker qualifies for a child tax benefit, and where, therefore, the actual gender of the speaker's children becomes irrelevant.

CONTEXT: Having a son or a daughter grants taxpayers certain benefits, compared to having no children. The speaker wants to claim such a tax benefit.

I (do) have a son or a daughter and, therefore, I am eligible for a tax benefit.

$\not \rightarrow$ The speaker is ignorant about whether he has a son

$\not \rightarrow$ The speaker is ignorant about whether he has a daughter

\footnotetext{
${ }^{30}$ This rule of thumb holds for all the cases which matter for us, namely those cases in which disjunctive sentences readily give rise to seemingly non-cancellable ignorance inferences. There are two main exceptions to this rule, having to do with cases like (i) and (ii):

(i) A: Did the candidate take Logic or Algebra?

B: Yes, she did (take Logic or Algebra).

(ii) Either the candidate took Logic, or I'm the King of France.

In the first case, a disjunctive sentence is uttered as an answer to a yes-no question. In this case, the partition of the context set associated with the question has two cells, one in which the candidate didn't take either subject, and one in which she took at least one of them and possibly both. Given this partition, the disjunction is relevant (Logic or Algebra), but neither its independent disjuncts (Logic, Algebra) nor their conjunction (Logic and Algebra) are. Crucially, as expected on a relevance-based approach, we observe that no exclusivity or ignorance implicature is drawn from B's reply in this context. The same observation holds of the second case in (ii): these are cases where, given the evident falsity of the second disjunct, the hearer will conclude that the candidate took Logic (see among others Simons 2001; Chemla 2010).
} 
We will now see that this line of explanation extends to disjunctive presuppositions, accounting for our novel cases of presupposed speaker's ignorance.

\subsubsection{Presupposed speaker's ignorance}

Given some natural assumption about the Matrix K operator, Meyer's (2013) proposal can be integrated into the M\&M system so as to account for the presuppositional variants of (72). In Marty and Romoli (2021), this is done by refining the semantics of $\mathrm{K}$ as shown in (75), so as to offer a proper treatment of presuppositions. In a nutshell, (75) states that presuppositions project universally under K. ${ }^{31}$ As Marty and Romoli (2021) note, this refinement simply corresponds to what is predicted by standard accounts of presupposition projection under attitude predicates (see Heim 1992, among others).

$$
\left[\left[K_{x} S_{p}\right]\right]=\lambda w: \forall w^{\prime} \in \operatorname{Dox}(x)(w)\left[p\left(w^{\prime}\right)\right] . \forall w^{\prime} \in \operatorname{Dox}(x)(w)\left[\left[\left[S_{p}\right]\right]\left(w^{\prime}\right)\right]
$$

With this refinement in place, we turn to show that a similar explanation as that given above for (72) extends to speaker-oriented presupposed ignorance cases like (76):

Noah is unaware that John speaks French or Japanese.

a. Presupposed exclusivity implicature:

$\rightsquigarrow$ The speaker believes that John doesn't speak French and Japanese

b. Presupposed ignorance inferences:

$\rightsquigarrow$ The speaker is ignorant about whether John speaks French

$\rightsquigarrow$ The speaker is ignorant about whether John speaks Japanese

The sentence in (76) conveys the same exclusivity and ignorance implicatures as the ones in (72). However, in the case of (76), these implicatures can only be derived on the basis of its presuppositional competitors. In a system combining M\&M's approach with Meyer's (2013) proposal - let us call it the MM\&M system - the pattern of inference in (76) can be derived in a way completely parallel to what we saw in (73), by means of the parse in (77).

$\left[\mathrm{EXH}_{(1)}\left[K_{S}\left[\mathrm{EXH}_{(2)}[\right.\right.\right.$ Noah is unaware that John speaks French or Japanese $\left.\left.]\right]\right]$

To explain why (77) gets us the desired results, consider first the logically nonweaker alternatives to $\mathrm{EXH}_{(2)}$ 's prejacent schematised in (78a): these alternatives are all Strawson-entailed by $\mathrm{EXH}_{(2)}$ 's prejacent, i.e., [Noah is unaware that $\mathrm{F}$ or J] $[\mathrm{F}$ or J], and therefore they all qualify as presuppositional alternatives. Of those presuppositional alternatives, only the one with the conjunctive presupposition, namely [F and $\mathrm{J}$, is innocently excludable, (78b). The outcome of this first exhaustification process is thus as shown in (78c): it is asserted that Noah is unaware that John speaks French or Japanese, and it is presupposed that John speaks French or Japanese but not both,

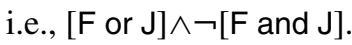

\footnotetext{
${ }^{31}$ Here and in the following, we use the notation ' $S_{p}$ ' to represent any sentence $S$ with presupposition $p$. This notation is only meant to facilitate the understanding of the examples we will work through.
} 
a. $\quad \operatorname{ALT}^{\text {prs }}(2)=\left\{\begin{array}{l}{[\text { Noah is unaware that } \mathrm{F}]_{\mathrm{F}},} \\ {[\text { Noah is unaware that } \mathrm{J}]_{\mathrm{J}},} \\ {[\text { Noah is unaware that } \mathrm{F} \text { and } \mathrm{J}]_{[\mathrm{F} \text { and } \mathrm{J}]}}\end{array}\right\}$

b. $\quad \mathrm{IE}^{\mathrm{prs}}(2 \mathrm{2})=\left\{[\text { Noah is unaware that } \mathrm{F} \text { and } \mathrm{J}]_{[\mathrm{F} \text { and } \mathrm{J}]}\right\}$

c. $\mathrm{EXH}_{2}$ [Noah is unaware that John speaks French or Japanese]

(i) Presupposition: [F or $\mathrm{J}] \wedge \neg[\mathrm{F}$ and $\mathrm{J}]$

(ii) Assertion: Noah is unaware that $[\mathrm{F}$ or $\mathrm{J}]$

As before, this result does not by itself account for the full pattern of inferences in (76). However, once we put it together with the rest of the LF in (77), we derive the presupposed ignorance inferences we are after. To see this, consider first the set of structural alternatives to $\mathrm{EXH}_{(1)}$ 's prejacent in (79); all of them are logically nonweaker than $\mathrm{EXH}_{(1)}$ 's prejacent and thus potential candidates for exclusion.

$$
\operatorname{ALT}(1)=\left\{\begin{array}{l}
{\left[K_{S}\left[\mathrm{EXH}_{(2)}[\text { Noah is unaware that } \mathrm{F}]\right]\right]_{K_{s}}[\mathrm{~F} \wedge \mathrm{J}]} \\
{\left[K_{S}\left[\mathrm{EXH}_{2}[\text { Noah is unaware that } \mathrm{J}]\right]\right]_{K_{S}[\mathrm{~J} \wedge \mathrm{F}]},} \\
{\left[K_{S}\left[\mathrm{EXH}_{2}[\text { Noah is unaware that } \mathrm{F} \text { and J] }]\right]\right]_{K_{s}}[\mathrm{~F} \text { and J]},} \\
{\left[K_{S}[\text { Noah is unaware that } \mathrm{F}]\right]_{K_{S}[\mathrm{~F}]},} \\
{\left[K_{S}[\text { Noah is unaware that } \mathrm{J}]\right]_{K_{s}[\mathrm{~J}]},} \\
{\left[K_{S}[\text { Noah is unaware that } \mathrm{F} \text { and J] }] K_{K_{s}[\mathrm{~F} \text { and J] }}\right.}
\end{array}\right\}
$$

The last three alternatives in (79), those without $\mathrm{EXH}_{(2)}$, are presuppositional alternatives: they carry stronger presuppositions and they are Strawson-entailed by EXH(1)'s prejacent. By contrast, the first three alternatives, those with $\mathrm{EXH}_{(2)}$, are assertive alternatives: they all carry stronger conjunctive presuppositions, but they are not Strawson-entailed. Thus for instance, on its strengthened meaning, the alternative $\left[K_{s}\left[\mathrm{EXH}_{2}\left[\right.\right.\right.$ Noah is unaware that F]]] is equivalent to $\left[K_{s}\right.$ [Noah is unaware that $\mathrm{F}] \wedge[$ Noah is aware that J]], which, by the projection rules we assume, presupposes $K_{s}[\mathrm{~F} \wedge \mathrm{J}]$. The sets of excludable presuppositional and assertive alternatives to $\mathrm{EXH}_{(1)}$ 's prejacent are thus as shown in (80a) and (80b).
a. $\quad \mathrm{E}^{\text {prs }}(1 \mathrm{1})=\left\{\begin{array}{l}{\left[K_{s}[\text { Noah is unaware that } \mathrm{F}]\right]_{K_{s}[\mathrm{~F}]},} \\ {\left[K_{s}[\text { Noah is unaware that } \mathrm{J}]\right]_{K_{s}[\mathrm{~J}]},} \\ {\left[K_{S}[\text { Noah is unaware that } \mathrm{F} \text { and J] }] K_{K_{s}[\mathrm{~F} \text { and J] }}\right.}\end{array}\right\}$
b. $\quad \mathrm{E}^{a s r}(1)=\left\{\begin{array}{l}{\left[K_{S}\left[\mathrm{EXH}_{(2)}[\text { Noah is unaware that } \mathrm{F}]\right]\right]_{K_{s}[\mathrm{~F} \wedge \mathrm{J}]},} \\ {\left[K_{s}\left[\mathrm{EXH}_{2}[\text { Noah is unaware that } \mathrm{J}]\right]\right]_{K_{S}[\mathrm{~J} \wedge \mathrm{F}]},} \\ {\left[K_{s}\left[\mathrm{EXH}_{(2)}[\text { Noah is unaware that } \mathrm{F} \text { and } \mathrm{J}]\right]\right]_{K_{s}[\mathrm{~F} \text { and J]}]}}\end{array}\right\}$

The next step is to determine the sets of $\mathrm{IE}^{p r s}$ and $\mathrm{IE}^{a s r}$ alternatives. For the presuppositional alternatives, it is easy to verify that the presuppositions of the alternatives in (80a) can be consistently negated all at the same time without contradicting EXH(1)'s prejacent. Therefore, the alternatives in (80a) are all $\mathrm{IE}^{\mathrm{prs}}$ alternatives, as stated in (81a). The presuppositional implicatures associated with them are given in (81b).

a. $\quad \operatorname{IE}{ }^{p r s}(1)=\left\{\begin{array}{l}{\left[K_{S}[\text { Noah is unaware that } \mathrm{F}]\right]_{K_{s}[\mathrm{~F}]},} \\ {\left[K_{S}[\text { Noah is unaware that } \mathrm{J}]\right]_{K_{s}[\mathrm{~F}]}} \\ {\left[K_{S}[\text { Noah is unaware that } \mathrm{F} \text { and J] }]\right]_{K_{s}[\mathrm{~F} \text { and J] }}}\end{array}\right\}$

b. Presuppositional implicatures: $\neg K_{S}[\mathrm{~F}], \neg K_{S}[\mathrm{~J}], \neg K_{S}[\mathrm{~F}$ and J] 
Recall now that the set of $\mathrm{IE}^{a s r}$ alternatives corresponds to the intersection of all maximal sets of assertive alternatives that can be negated consistently with the prejacent and the negation of the presupposition of all $\mathrm{IE}^{\text {prs }}$ alternatives. In the present case, all the assertive alternatives in (80b) carry the conjunctive presupposition $K_{s}[\mathrm{~F}$ and J]. Since this presupposition is inconsistent with the presuppositional implicatures above, none of them is innocently excludable (i.e., $\operatorname{IE}^{a s r}(1)=\emptyset$ ), and therefore, $\mathrm{EXH}_{(1)}$ 's prejacent doesn't give rise to any assertive implicature. We end up for (77) with the final representation in (82): it is asserted that the speaker believes that Noah is unaware that John speaks French or Japanese, and it is presupposed that (i) the speaker believes that John speaks French or Japanese but not both (from (78) by projection), and that (ii) the speaker is ignorant as to whether John speaks French and as to whether John speaks Japanese (from (i) and (81)).

$\left[\mathrm{EXH}_{(1)}\left[K_{S}\left[\mathrm{EXH}_{(2)}[\right.\right.\right.$ Noah is unaware that John speaks French or Japanese $\left.\left.]\right]\right]$

a. Presupposition: $K_{S}[[\mathrm{~F}$ or $\mathrm{J}] \wedge \neg[\mathrm{F}$ and $\mathrm{J}]] \wedge I_{S}[F] \wedge I_{S}[J]$

b. Assertion: $\quad K_{S}[$ Noah is unaware that $\mathrm{F}$ or J]

Just as before, our assumptions about the calculation of relevance for disjunctive sentences make it so that the presuppositional alternatives to $\mathrm{EXH}_{\mathbb{1}}$ 's (disjunctive) prejacent, which presuppose the independent disjuncts, are likely to be construed as relevant alternatives by the hearers; if that is the case, then these alternatives and their presuppositions cannot be pruned from the domain of quantification of $\mathrm{EXH}_{(1)}$, which in turn makes the presuppositional implicatures $\neg K_{S}[\mathrm{~F}]$ and $\neg K_{S}[\mathrm{~J}]$ obligatory. ${ }^{32}$ The generation of these inferences in run-of-the-mill contexts accounts for Marty \& Romoli's observation that the infelicity effects in (45) reproduce in embedded cases like (44).

a. \#Noah is unaware that I have a son or a daughter.

b. \#Sue didn't realise that my wife was born in France or in Japan.

c. \#Mary was sorry that Sue had lunch with Noah or me yesterday.

It is worth emphasising, here again, that this description is only a rule of thumb and that it does not apply if the context of utterance is sufficiently determined so that neither of the presuppositions of the independent disjuncts is relevant to the topic of conversation. In such cases, the sentences in (44) should not give rise to ignorance inferences and, therefore, are predicted to be acceptable. This prediction is empirically borne out. As exemplified in (83), a sentence like (44a) is felicitous in a context where all it matters to know is whether or not the speaker's accountant, Noah, knows that the speaker qualifies for a child tax benefit.

\footnotetext{
${ }^{32}$ This result relies on the fact that, if a sentence $S_{p}$ is relevant given a partition $Q$, then its presupposition $p$ is also relevant given $Q$. A short proof of this fact can be given by reductio ad absurdum. For the argument, suppose that $S_{p}$ is relevant given $Q$, but that $p$ is not. Since $p$ isn't relevant, then, for some cell $q \in Q$ and some worlds $w, w^{\prime} \in q$, we have $p(w) \neq p\left(w^{\prime}\right)$. It follows then that, for some cell $q \in Q$ and some worlds $w, w^{\prime} \in q$, we also have $S_{p}(w) \neq S_{p}\left(w^{\prime}\right)$. But it then further follows that $S_{p}$ is not relevant given $Q$; a contradiction obtains. Therefore, $p$ must be relevant given $Q$ if $S_{p}$ is.
} 
(83) CONTEXT: Having a son or a daughter grants taxpayers certain benefits, compared to having no children. The speaker is eligible for such a tax benefit but he thinks that his accountant, Noah, lacks the relevant information.

Noah is unaware that I have a son or a daughter and, therefore, he may be mistaken about which tax bracket I am in.

$\not \rightarrow$ The speaker is ignorant about whether he has a son

$\Varangle \rightarrow$ The speaker is ignorant about whether he has a daughter

To summarise, integrating Meyer's (2013) proposal with the M\&M approach, as recently proposed by Marty and Romoli (2021), offers a way to derive presupposed ignorance inferences in the grammar and to account at the same time for the fact that those inferences are speaker-oriented. We will now see that the MM\&M approach also captures the cases of presupposed ignorance involving the additive particle too, as well as its problematic variants, thus addressing the presupposed ignorance challenge in full.

\subsubsection{Presupposed common ignorance and its variants}

The MM\&M approach permits us to explore in detail the interactions between too and the ignorance implicatures discussed in $(72) /(73)$ and, in particular, to study how the additional use of too affects the presupposition of these implicatures and subsequently the presuppositional strength of the whole sentence. So consider the variant of (72) where, as before, the focus-sensitive particle too associates with the focused element John:

$\mathrm{John}_{F}$, too, speaks French or Japanese.

On the MM\&M approach, this sentence allows different parses, which differ in terms of the scopal relations between too and the mechanisms responsible for ignorance inferences. As a starting point, consider the parse in (85), where too occurs below K, while an instance of EXH occurs below it to associate with the disjunction or. ${ }^{33}$

$\mathrm{EXH}_{(1)}\left[\mathrm{K}_{s}\left[\operatorname{too}\left[\mathrm{John}_{F} \lambda x \mathrm{EXH}_{(2)}[x\right.\right.\right.$ speaks French or Japanese $\left.\left.\left.]\right]\right]\right]$

a. Exhaustification below $\mathrm{K}$ and too:

(i) $\mathrm{IE}^{a s r}=\{[\mathrm{F}$ and $\mathrm{J}]\}$

(ii) Implicature: $\neg[\mathrm{F}$ and $\mathrm{J}]$

b. Presupposition projecting under too following (a):

$\rightsquigarrow$ Some salient $x$ distinct from John speaks F. or J., but not both

c. Exhaustification above $\mathrm{K}$ and too:

(i) $\mathrm{IE}^{a s r}=\left\{\begin{array}{c}{\left[\mathrm{K}_{s} \mathrm{EXH}_{2} \text { too } \mathrm{F}\right],\left[\mathrm{K}_{s} \mathrm{EXH}_{2} \text { too } \mathrm{J}\right],} \\ {\left[\mathrm{K}_{s} \mathrm{EXH}_{2} \text { too } \mathrm{F} \text { and J], }\right.} \\ {\left[\mathrm{K}_{s} \text { too } \mathrm{F}\right],\left[\mathrm{K}_{s} \text { too }\right],\left[\mathrm{K}_{s} \text { too } \mathrm{F} \text { and } \mathrm{J}\right]}\end{array}\right\}$

(ii) Implicatures: $\neg \mathrm{K}_{s}$ [too $\left.\mathrm{F} \wedge \neg \mathrm{J}\right], \neg \mathrm{K}_{s}$ [too $\left.\mathrm{J} \wedge \neg \mathrm{F}\right], \neg \mathrm{K}_{s}$ [too $\mathrm{F}$ ], $\neg \mathrm{K}_{s}[$ too $\mathrm{J}]$

${ }^{33}$ We thank Uli Sauerland for discussion of these data and analytical options. 
d. Additional presuppositions triggered by too following (c):

$\rightsquigarrow$ Some salient $x$ distinct from John speaks F. but not $J$.

$\rightsquigarrow$ Some salient y distinct from John speaks J. but not F.

On this parse, the particle too and our set of implicatures interact in two different ways. First, an exclusivity implicature is computed in the scope of too, (85a), which gives us the presupposition that some salient $x$ distinct from John speaks French or Japanese, but not both, (85b). Second, ignorance inferences are computed on the basis of alternatives including too, $(85 \mathrm{c})$, which gives us by projection the additional presuppositions that some salient $x$ distinct from John speaks French but not Japanese and some salient y distinct from John speaks Japanese but not French, (85d). On this parse, the sentence in (84) presupposes therefore that there are two salient individuals $x, y$, distinct from John, such that $x$ speaks French but not Japanese and $y$ speaks Japanese but not French. This analysis correctly predicts (84) to be felicitous in a context where a split conjunctive antecedent is available, as in (86a), and correctly predicts (84) to be infelicitous in contexts where only a simple or a non-split conjunctive antecedent is available, as in (86b) and (86c). However, this parse does not explain why (84) is also felicitous with genuine disjunctive antecedents, as in (86d).

(86) Predictions from the first parse in (85) (assuming the general context in (65))

a. Split conjunctive antecedent

Context: Mary speaks French and Bill speaks Japanese.

John, too, speaks French or Japanese.

$\checkmark$ Predicted: Ok, Observed: $O k$

b. Simple antecedent

Context: Mary speaks French.

\#John, too, speaks French or Japanese.

$\checkmark$ Predicted: Odd, Observed: Odd

c. Non-split conjunctive antecedent

Context: Mary speaks French and Japanese.

\#John, too, speaks French or Japanese.

$\checkmark$ Predicted: Odd, Observed: Odd

d. Disjunctive antecedent

Context: Mary speaks French or Japanese.

John, too, speaks French or Japanese.

xPredicted: Odd, Observed: $O k$

The felicity of (84) with disjunctive antecedents is, however, accounted for once we consider another possible parse for (84), on which too takes scope over the whole sentence as follows:

too $\left[\mathrm{EXH}_{(1)}\left[\mathrm{K}_{s}\left[\operatorname{John}_{F} \lambda x \mathrm{EXH}_{(2)}[x\right.\right.\right.$ speaks French or Japanese $\left.\left.]\right]\right]$

a. Exhaustification below $\mathrm{K}$ :

(i) $\mathrm{IE}^{\text {asr }}=\{[\mathrm{F}$ and $\left.\mathrm{J}]]\right\}$

(ii) Implicature: $\neg[\mathrm{F}$ and $\mathrm{J}]$ 
b. Exhaustification above $\mathrm{K}$ :

(i) $\mathrm{IE}^{a s r}=\left\{\begin{array}{c}{\left[\mathrm{K}_{s} \mathrm{EXH}_{(2)} \mathrm{F}\right],\left[\mathrm{K}_{s} \mathrm{EXH}_{(2)} \mathrm{J}\right],\left[\mathrm{K}_{s} \mathrm{EXH}_{(2)} \mathrm{F} \text { and J], }\right.} \\ {\left[\mathrm{K}_{s} \mathrm{~F}\right],\left[\mathrm{K}_{s} \mathrm{~J}\right],\left[\mathrm{K}_{s} \mathrm{~F} \text { and J] }\right.}\end{array}\right\}$

(ii) Implicatures: $\neg \mathrm{K}_{s}[\mathrm{~F} \wedge \neg \mathrm{J}], \neg \mathrm{K}_{s}[\mathrm{~J} \wedge \neg \mathrm{F}], \neg \mathrm{K}_{s}[\mathrm{~F}], \neg \mathrm{K}_{s}[\mathrm{~J}]$

c. Presuppositions triggered by too following (a) and (b):

$\rightsquigarrow$ Some salient $x$ distinct from John speaks $F$. or J. but not both, but the speaker is ignorant as to whether $x$ speaks $F$. and as to whether $x$ speaks $J$.

On this second parse, all implicatures are computed in the scope of too, which results in the presupposition in (87c): some salient $x$ distinct from John speaks French or Japanese but not both, and the speaker is ignorant about whether $x$ speaks French and whether $x$ speaks Japanese. As a result, this parse is only compatible with antecedents expressing similar forms of ignorance on the part of the speaker towards some individual other than John. The predictions for split conjunctive and disjunctive antecedents in (85) are now reversed, while, crucially, the predictions for the simple antecedent and the non-split conjunctive antecedents are the same as before; that is, they are both predicted to be infelicitous under this parse as well.

(88) Predictions from the second parse in (87) (assuming the general context in (65))

a. Split conjunctive antecedent

Context: Mary speaks French and Bill speaks Japanese.

John, too, speaks French or Japanese.

XPredicted: Odd, Observed: $O k$

b. Simple antecedent

Context: Mary speaks French.

\#John, too, speaks French or Japanese.

$\checkmark$ Predicted: Odd, Observed: Odd

c. Non-split conjunctive antecedent

Context: Mary speaks French and Japanese.

\#John, too, speaks French or Japanese.

$\checkmark$ Predicted: Odd, Observed: Odd

d. Disjunctive antecedent

Context: Mary speaks French or Japanese.

John, too, speaks French or Japanese.

$\checkmark$ Predicted: Ok, Observed: $O k$

In sum, we have shown that S\&S's proposal fails to extend to some variants of their second motivating case. In reply to these challenges, we have proposed an alternative account of the previous and new data based on the interactions of the particle too with the ignorance inferences associated with disjunctive sentences, and shown that these interactions allow different parses which can license either split conjunctive or disjunctive antecedents, but neither simple nor non-split conjunctive antecedents. The resulting account was shown to reproduce the predictions of S\&S's system for the basic case of presupposed common ignorance and to extend to its variants. In the following, we turn to briefly discussing how Meyer's proposal can be integrated with 
the PIP and the LI approach, and how the resulting systems fare with respect to the presupposed ignorance cases.

\subsection{Other approaches}

We discussed how adding Meyer's (2013) proposal to M\&M's approach accounts for the presupposed ignorance cases. Can we achieve the same results with the other two approaches? That is, can we add K to the system of Spector and Sudo (2017) or Anvari (2018) to account for these cases? To explore this question, consider adding $\mathrm{K}$ to a system that includes the exhaustivity operator from S\&S (see definition in (9)) together with a pragmatic principle like the PIP or LI, and consider again a case of speaker-oriented ignorance like (89):

\#Noah is unaware that I speak French or Japanese.

As a first step, we can look at the parse in (90), which involves $\mathrm{K}$ but no EXH, the presupposition of which is that the speaker believes that he speaks French or Japanese.

$\left[\mathrm{K}_{s}[\text { Noah is unaware that I speak French or Japanese }]\right]_{K_{s}}[\mathrm{~F}$ or J]

The alternatives to consider on this parse also include $\mathrm{K}$, as illustrated in (91a) and (91b). Note that the presuppositions of those alternatives are stronger than that of (90) and logically independent from their counterparts without K: they presuppose that the speaker believes that he speaks French, and that the speaker believes that he speaks Japanese, respectively.

$$
\begin{array}{ll}
\text { a. } & {\left[\mathrm{K}_{s}[\text { Noah is unaware that I speak French }]\right]_{K_{s}[\mathrm{~F}]}} \\
\text { b. } & \left.\left[\mathrm{K}_{s} \text { [Noah is unaware that I speak Japanese }\right]\right]_{K_{S}[\mathrm{~J}]}
\end{array}
$$

It is easy to imagine a context in which the presuppositions of (91a) and (91b) are not satisfied, i.e., a context in which it is not commonly known whether the speaker believes that he speaks French and whether he believes that he speaks Japanese. While (89) remains infelicitous in such contexts, a principle like the PIP cannot account for its infelicity, because the presuppositions of (91a) and (91b) are not satisfied. Similarly, LI cannot account for the infelicity of (90) either: in such contexts, (90) does not contextually entail either of (91a) and (91b). ${ }^{34}$ Crucially, we note that adding an occurrence of S\&S's exhaustivity operator below and/or above $\mathrm{K}$, as shown in (92), does not change the situation, since their exhaustivity operator is predicted to be vacuous here, in both positions.

$$
\mathrm{EXH}_{(1)}\left[K_{S}\left[\mathrm{EXH}_{(2)}[\text { Noah is unaware that I speak French or Japanese }]\right]\right.
$$

\footnotetext{
${ }^{34}$ It is conceivable that something along the lines of (i) is naturally assumed by the interlocutors in a normal conversation. Yet as far as we can see, making that assumption common ground would not solve the issue at hand: (i) does not permit the presuppositions of (91a) and (91b) to be satisfied in the context, nor does it permit (90) to contextually entail (91a) or (91b).
}

(i) If an individual $x$ speaks a language $L$, then $x$ knows that $x$ speaks $L$. 
Finally, let us consider the presupposed common ignorance cases. For these cases, adding the K-operator to S\&S's system helps with only one of the problematic variants of presupposed common ignorance, repeated below. Specifically, it helps in correctly predicting the felicity of (67b), but it does not help with the incorrect prediction about (67a).
a. Variant 1: Non-split conjunctive antecedent
Context: Mary speaks French and Japanese.
$\# \mathrm{John}_{F}$, too, speaks French or Japanese.
b. Variant 2: Split conjunctive antecedent
Context: Mary speaks (only) French and Bill speaks (only) Japanese.
$\mathrm{John}_{F}$, too, speaks French or Japanese.

To illustrate, consider the non-split conjunctive antecedent case first, and assume that it is common ground that Mary speaks French and Japanese and that the speaker believes that Mary speaks French and Japanese. Recall that the problem for S\&S was that, while (67a) appears infelicitous in this context, there is a parse of it under which it is incorrectly predicted to be felicitous, namely (69).

\section{EXH [too [John $F$ speaks French or Japanese]]}

If we append $\mathrm{K}$ to this parse, as in (93), the assertion becomes that the speaker believes that John speaks French or Japanese but not both, and the presupposition becomes that some salient individual other than John speaks both French and Japanese. This presupposition obtains by projecting the presupposition of the negated conjunctive alternative to EXH's prejacent, which includes the presupposition trigger too. Once again, that presupposition is satisfied in the context of (67a), and no alternative has a stronger presupposition. Hence, under this parse, the sentence is still incorrectly predicted to be felicitous.

$$
\mathrm{K}_{s}\left[\mathrm { EXH } \left[\text { too } \left[\mathrm{John}_{F}\right.\right.\right. \text { speaks French or Japanese]]] }
$$

Let us now turn to the split conjunctive antecedent case, (67b), and see how $\mathrm{K}$ can help in this case. Recall that the problem there was that, under all parses, (67b) was incorrectly predicted to be infelicitous. The question in this case is whether adding $\mathrm{K}$ to any of those parses would help. To address this question, let us refine the context above by assuming that the speaker knows that Mary speaks only French and that Bill speaks only Japanese, and consider each of the parses in (94) in turn.

$$
\begin{array}{ll}
\text { a. } & \mathrm{K}_{s}\left[\text { too } \left[\operatorname{John}_{F}\right.\right. \text { speaks French or Japanese]] } \\
\text { b. } & \mathrm{K}_{s}\left[\mathrm { EXH } \left[\text { too } \left[\mathrm{John}_{F}\right.\right.\right. \text { speaks French or Japanese]]] } \\
\text { c. } & \mathrm{EXH}\left[\mathrm { K } _ { s } \left[\text { too } \left[\mathrm{John}_{F}\right.\right.\right. \text { speaks French or Japanese]]] }
\end{array}
$$

It is easy to see that (94a) and (94b) are still predicted to be infelicitous. (94a) is deemed infelicitous by the PIP because of the alternatives in (95a) and (95b), both of which have stronger presuppositions which are satisfied in the context (i.e., the speaker knows that someone other than John speaks French and that some other individual speaks Japanese). Adding EXH below $\mathrm{K}$ does not improve on that result: if an exclusivity implicature is computed in the scope of $\mathrm{K}$, then (94b) gives rise to 
the presupposition that the speaker believes that some salient individual other than John speaks both French and Japanese, but that presupposition is not satisfied; if that implicature is suspended, then (94b) amounts to (94a) and, therefore, it is deemed infelicitous by the PIP for the same reason as (94a).

$$
\begin{array}{ll}
\text { a. } & {\left[\mathrm{K}_{s}\left[\text { too }\left[\mathrm{John}_{F} \text { speaks French }\right]\right]\right]_{K_{s}[\mathrm{~F}]}} \\
\text { b. } & {\left[\mathrm{K}_{s}\left[\text { too }\left[\mathrm{John}_{F} \text { speaks Japanese }\right]\right]\right]_{K_{s}[\mathrm{~J}]}}
\end{array}
$$

The last parse in (94c), however, has the potential to make the right prediction: if the exhaustification process above $\mathrm{K}$ is performed against the formal alternatives in (95), we can now derive the implicatures $\neg\left[K_{s}[\text { too } \mathrm{F}]\right]_{K_{s}[\mathrm{~F}]}$ and $\neg\left[K_{s}[\text { too } \mathrm{J}]\right]_{K_{s}[\mathrm{~J}]}$, which convey that the speaker isn't sure that John (also) speaks French and that the speaker isn't sure that John (also) speaks Japanese, while adding the presupposition that the speaker believes that someone other than John speaks French and the presupposition that the speaker believes that someone other than John speaks Japanese. ${ }^{35}$ Both presuppositions are satisfied in the context and, crucially, they strengthen the meaning of the target sentence in a way that renders the application of the PIP vacuous. In particular, one can verify that the presuppositions derived for $(94 \mathrm{c})$ correspond to the conjunction of the presuppositions of the alternatives in (95).

In sum, integrating the Matrix K operator with S\&S's system does not help with the incorrect prediction in the non-split antecedent case in (67a), but it allows to correctly predict the felicity of (67b) on a parse along the lines of (94c). This is essentially similar to the line of explanation we proposed in (85) when exploring the predictions of the MM\&M approach. We take this last result to provide further evidence that integrating $\mathrm{K}$ into $\mathrm{S} \& \mathrm{~S}$ 's system may in fact be a necessary addition in order to further temper the application of the PIP (see fn. 23 for discussion). Nonetheless, such an addition remains insufficient to solve all of the problematic cases. We therefore conclude for now that the resulting systems do not fully address the presupposed ignorance challenge.

\section{Discussion}

As a principle of language use, Maximize Presupposition! (MP) offers an account of the (un)assertability of a variety of sentences against given contextual information. As we discussed, at the core of MP is the idea that a sentence is infelicitous in a given context if it has an alternative that contributes the same new information but carries a stronger presupposition that is satisfied in the context. Recently, the empirical adequacy of this principle has been challenged by the observation of novel cases which do not seem to meet the classical MP-conditions in regard to the underlying competition which could account for their infelicity. This has led some researchers

\footnotetext{
${ }^{35}$ Note that it is critical in this case to assume that the conjunctive alternative of the form $\left[K_{S}\right.$ [too $\mathrm{F}$ and $\mathrm{J}]]_{K_{S}}[\mathrm{~F}$ and $\mathrm{J}]$ is pruned from the domain of EXH, for the implicature associated with that alternative would otherwise add the false presupposition that the speaker believes that some contextually salient individual other than John speaks both French and Japanese.
} 
Table 1 Comparison of the four different approaches to MP and MP-like phenomena investigated in this paper along logical and contextual criteria

\begin{tabular}{lll}
\hline & Logical criterion & Contextual criterion \\
\hline MP & Stronger presupposition & Satisfaction and contextual equivalence \\
PIP & Stronger presupposition & Satisfaction \\
LI & Non-weaker alternatives & Contextual entailment \\
Implicature & IE $^{\text {prs }}$ alternatives & Relevance of presuppositions \\
\hline
\end{tabular}

to propose less restrictive principles, the PIP or LI, relaxing one or more of the original MP-conditions, starting with the requirement that presuppositional competitors be contextually equivalent to their base sentence.

In this paper, we presented a body of evidence showing that these novel principles are sometimes too liberal, sometimes too restrictive: they overgenerate infelicity for a variety of felicitous cases while leaving the infelicity of minimally different cases unaccounted for. We next turned our attention to an alternative account based on the grammatical theory of scalar implicatures stemming from Magri (2009), Marty (2017, 2019b), and Marty and Romoli (2021), which subsumes the MP-conditions on contextual equivalence and presupposition satisfaction under the broader notion of relevance. This approach was found to account for one of the three overgeneration cases we raised, the case of cardinal partitives, yet to run into similar problems as the PIP and LI for the other two. We have also shown that, once combined with Meyer's (2013) approach to ignorance implicatures, this approach can account for the presupposed ignorance challenge in full, capturing the original cases by Spector and Sudo (2017) and the problematic variants that we unveiled in this paper. As we discussed, while Meyer's (2013) proposal is also compatible with the PIP and LI, the resulting systems remain unable to achieve similar results as they stand.

Thus, the present investigation offers a systematic comparison of four approaches to MP and MP-like phenomena for a wide range of old and novel cases. These all differ in critical ways from one another with respect to how they define the presuppositional competitors to a given sentence and consequently with respect to the conditions under which they predict infelicity effects to arise, as summarised in Table 1.

The predictions of the approaches for each of the cases we studied are synthesized in Table 2. One potential benefit of the results summed up in this table is that they provide concrete baselines for evaluating the advantages and drawbacks of each approach and, more generally, for considering the trade-offs between the kinds of criteria imposed on competing alternatives and the resulting empirical coverage of the different approaches, e.g., by identifying the theoretical moves that permit us to account for additional phenomena, albeit sometimes at the cost of subsequent overgeneration issues.

One interesting finding of this investigation is that none of the accounts we have investigated, including the mentioned variants, can satisfyingly capture all the cases discussed in the paper. In other words, the issue of how to properly restrict the competition for MP-like cases, accounting for the classical cases, those of Spector and Sudo (2017), and the novel ones we presented here, remains an open challenge for all accounts in the literature. In particular, two cases remain challenging for all three 
Table 2 Comparison of the four approaches with respect to the cases discussed: a green ' $\checkmark$ ' indicates that an approach makes correct predictions for the relevant case, a blue ' $x$ ' that it leaves the case unaccounted for, and a red ' $x$ ' that it makes incorrect predictions

\begin{tabular}{lccccc}
\hline & MP & PIP & LI & \multicolumn{2}{c}{ Implicature } \\
\cline { 4 - 5 } & & & & M\&M & MM\&M \\
\hline Classical MP cases & $\checkmark$ & $\checkmark$ & $\checkmark$ & $\checkmark$ & $\checkmark$ \\
Asymmetry & $\times$ & $\checkmark$ & $\checkmark$ & $\checkmark$ & $\checkmark$ \\
Presupposed common ignorance & $\times$ & $\checkmark$ & $\times$ & $\times$ & $\checkmark$ \\
Presupposed speaker's ignorance & $\times$ & $\times$ & $\times$ & $\times$ & $\checkmark$ \\
Cardinal partitives & $\checkmark$ & $\times$ & $\times$ & $\checkmark$ & $\checkmark$ \\
Existential presuppositions & $\checkmark$ & $\times$ & $\times$ & $\times$ & $\times$ \\
Restrictors & $\checkmark$ & $\times$ & $\times$ & $\times$ & $\times$ \\
\hline
\end{tabular}

non-MP accounts: the case of existential presuppositions and the case of restrictors, repeated below.

\section{Existential Presuppositions}

Context: It is common ground that all of the speaker's students used to smoke.

If some of my students stopped smoking, Jane will be happy.

\section{Restrictors}

Context: It is common ground that some students met with both Danny and Irene, and that Jane is possibly one of them.

a. All/Most/The students who met with Danny or Irene understood the puzzle.

b. If Jane met with Danny or Irene, she understood the puzzle.

As we explicitly stated, the problem of existential presuppositions is a problem only if one assumes that presuppositions do not project universally from the scope of existential quantifiers. Experimental support for this assumption is found, for instance, in Chemla 2009, which found endorsement of universal projection to vary among quantifiers and, crucially, to be lower in cases involving the scope of quantifiers like few/less than 3/many/most than in cases involving others, like each and none, suggesting that presuppositions project existentially or at least less-than-universally from the scope of the former. We note, however, that these findings remain in principle compatible with a theory like the one proposed in Schlenker 2009, in which presuppositions uniformly project universally from all quantifiers' scope, while some other mechanism would be responsible for the differences observed between quantifiers (e.g., local accommodation). On this alternative view, one could thus argue that, in cases like (51), what is relevant for the application of the different principles or mechanisms we discussed (PIP, LI, EXH) is not the observed existential presupposition but rather the predicted universal one, which would solve the problem of existential presuppositions.

The problem of restrictors may remain yet more recalcitrant. A possible way out would be to adopt a non-presuppositional analysis of the non-emptiness requirement 
on restrictors, as proposed in Abusch and Rooth (2005) and Schlenker (2012). One of the arguments for a non-presuppositional analysis comes for instance from examples like (96), adapted from Schlenker (2012, (62)). The observation here is that (96) does not convey that there is at some future time a student who gets a perfect score on the test; yet that is what (96) is expected to presuppose if will is used for future time reference in that sentence. ${ }^{36}$

(96) I'll give a bottle of wine to every student who gets a perfect score on the next test.

We note, however, that cases like (96) raise an issue for a presuppositional analysis only insofar as one assumes that will must receive a temporal reading. If we concede instead that will may be used as a modal here, thereby creating a nonveridical epistemic space (e.g., Giannakidou 2012; Giannakidou and Mari 2013, 2018) and conveying a conjectural reading (a.o., Palmer 1986; Sarkar 1998; Huddleston 1995; Enç 1996), then the issue fades away. On this modal use, (96) presupposes instead that in the most ideal worlds from the modal base, there is a student who gets a perfect score on the test, expressing the speaker's weak epistemic commitment to there being a student scoring perfectly on the next test as much as a positive bias towards that unsettled event. In support of this modal use of will in (96), we note for instance that its variant in (97) is infelicitous if it is common ground that no student may get a 100 on the next test ((97) is ok, of course, if it is understood to convey a touch of humour, precisely because of the speaker's harmless commitment).

Context: It is common ground that the next test will be marked out of 90 , with no extra credits.

\#I'll give a bottle of wine to every student who gets a 100 on the next test.

We further hint that cases like (96) may only work that way with future-oriented eventualities, precisely because of the possible modal use of will: in contrast to (96), its past-variant in (98) strongly suggests that there are students who got a perfect score on the last test.

I gave a bottle of wine to every student who got a perfect score on the last test.

Finally, and perhaps most importantly, while this line of explanation would solve the problem of restrictors for quantifiers like every, it would not extend to the restrictors of the or most; where the latter are concerned, proper restrictions on presuppositional competitors remain an interesting challenge for all non-MP approaches. We hope, therefore, that the present investigation will invite further work on the relationships between presupposition and scalar strengthening to engage with the issues left open here.

\footnotetext{
${ }^{36}$ Very similar considerations apply to analysing the compatibility inference of conditionals as something other than a presupposition (cf. Gazdar 1979).
} 


\section{Declarations}

Compliance with Ethical Standards The authors declare that they have no conflict of interest.

Open Access This article is licensed under a Creative Commons Attribution 4.0 International License, which permits use, sharing, adaptation, distribution and reproduction in any medium or format, as long as you give appropriate credit to the original author(s) and the source, provide a link to the Creative Commons licence, and indicate if changes were made. The images or other third party material in this article are included in the article's Creative Commons licence, unless indicated otherwise in a credit line to the material. If material is not included in the article's Creative Commons licence and your intended use is not permitted by statutory regulation or exceeds the permitted use, you will need to obtain permission directly from the copyright holder. To view a copy of this licence, visit http://creativecommons.org/licenses/by/ $4.0 \%$.

\section{References}

Abusch, Dorit, and Mats Rooth. 2005. Empty-domain effects for presuppositional and nonpresuppositional determiners. In Context-dependence in the analysis of linguistic meaning, eds. Hans Kamp and Barbara Partee, 7-27. Amsterdam: Elsevier.

Alonso-Ovalle, Luis, and Paula Menéndez-Benito. 2010. Modal indefinites. Natural Language Semantics 18(1): $1-31$.

Anvari, Amir. 2018. Logical integrity. In Proceedings of semantics and linguistic theory 28, eds. S. Maspong et al., 711-726. Washington: LSA.

Anvari, Amir. 2019. Logical Integrity. Manuscript, IJN-ENS.

Barker, Chris. 1998. Partitives, double genitives and anti-uniqueness. Natural Language and Linguistic Theory 16(4): 679-717.

Beaver, David, and Brady Z. Clark. 2009. Sense and sensitivity. How focus determines meaning. Oxford: Oxford University Press.

Bennett, Paul A. 1979. On Universal 23. Linguistic Inquiry 10(3): 510-511.

Buccola, Brian, and Andreas Haida. 2019. Obligatory irrelevance and the computation of ignorance inferences. Journal of Semantics 36(4): 583-616.

Charlow, Simon. 2009. "Strong" predicative presuppositional objects. Presented at New Directions in the Theory of Presupposition, ESSLLI 2009. https://simoncharlow.com/handouts/esslli_presup.pdf.

Chemla, Emmanuel. 2008. An epistemic step for anti-presuppositions. Journal of Semantics 25(2): $141-173$.

Chemla, Emmanuel. 2009. Presuppositions of quantified sentences: Experimental data. Natural Language Semantics 17(4): 299-340.

Chemla, Emmanuel. 2010. Similarity: Towards a unified account of scalar implicatures, free choice permission and presupposition projection. Manuscript, ENS.

Chierchia, Gennaro. 2006. Broaden your views: implicatures of domain widening and the "logicality" of language. Linguistic Inquiry 37(4): 535-590.

Enç, Murvet. 1996. Tense and modality. In Handbook of contemporary semantic theory, ed. Shalom Lappin, 345-358. Oxford: Blackwell.

Fox, Danny. 2007. Free choice and the theory of scalar implicatures. In Presupposition and implicature in compositional semantics, eds. Uli Sauerland and Penka Stateva, 71-120. London: Palgrave.

Fox, Danny. 2016. On why ignorance might not be part of literal meaning. Commentary on Marie-Christine Meyer at the MIT Workshop on Exhaustivity, 2016.

Fox, Danny, and Roni Katzir. 2011. On the characterization of alternatives. Natural Language Semantics 19(1): 87-107.

Fox, Danny, and Benjamin Spector. 2009. Economy and embedded exhaustification. Handout from a talk given at Cornell, MIT \& ENS.

Fox, Danny, and Benjamin Spector. 2018. Economy and embedded exhaustification. Natural Language Semantics 26(1): 1-50.

Gajewski, Jon, and Yael Sharvit. 2012. In defense of the grammatical approach to local implicatures. Natural Language Semantics 20(1): 31-57. 
Gazdar, Gerald. 1979. Pragmatics: Implicature, presupposition, and logical form. New York: Academic Press.

Giannakidou, Anastasia. 2012. The Greek future as an epistemic modal. In Proceedings of ICGL 10, 48-61. Available at: https://www.icgl.gr/en/.

Giannakidou, Anastasia, and Alda Mari. 2013. The future of Greek and Italian: An epistemic analysis. In Proceedings of Sinn und Bedeutung 17, eds. E. Chemla et al., 255-270. Available at: https:// semanticsarchive.net/sub2012/SuB2013.pdf.

Giannakidou, Anastasia, and Alda Mari. 2018. A unified analysis of the future as epistemic modality. Natural Language and Linguistic Theory 36(1): 85-129.

Groenendijk, J., and M. Stokhof. 1984. Studies on the semantics of questions and the pragmatics of answers, PhD dissertation, University of Amsterdam.

Groenendijk, J. A. G., T. M. V. Janssen, and M. B. J. Stokhof. 1984. Truth, interpretation and information: Selected papers from the Third Amsterdam colloquium. Dordrecht: Foris.

Heim, Irene. 1983. On the projection problem for presuppositions. In Proceedings of WCCFL 2, ed. Daniel P. Flickinger, 114-125. Stanford: CSLI Publications.

Heim, Irene. 1990. Presupposition projection. In Reader for the Nijmegen workshop on presupposition, lexical meaning, and discourse processes, ed. R. van der Sandt. University of Nijmegen.

Heim, Irene. 1991. Artikel und Definitheit. In Semantik: Ein internationales Handbuch der zeitgenössischen Forschung, eds. Arnim von Stechow and Dieter Wunderlich, 487-535. Berlin: de Gruyter.

Heim, Irene. 1992. Presupposition projection and the semantics of attitude verbs. Journal of Semantics 9 : 183-221.

Heim, Irene. 1994. Interrogative semantics and Karttunen's semantics for know. In Proceedings of IATL 1, eds. Rhonna Buchalla and Anita Mittwoch, 128-144. Hebrew University of Jerusalem.

Heim, Irene, and Angelika Kratzer. 1998. Semantics in generative grammar. Malden: Blackwell.

Hoeksema, Jacob. 1984. Partitives. Manuscript, University of Groningen.

Huddleston, Rodney. 1995. The case against a future tense in English. Studies in Language 19(2): 399-446.

Jackendoff, Ray. 1977. X-bar syntax: A study of phrase structure. Cambridge: MIT Press.

Karttunen, Lauri. 1974. Presupposition and linguistic context. Theoretical Linguistics 1: 181-194.

Katzir, Roni, and Raj Singh. 2013. A note on presupposition accommodation. Semantics and Pragmatics 6: $1-5$.

Krifka, Manfred. 1998. Additive particles under stress. In Proceedings of SALT VIII, eds. Devon Strolovitch and Aaron Lawson, 111-129. Ithaca: CLC Publications.

Kripke, Saul. 2009. Presupposition and anaphora. Linguistic Inquiry 40(3): 1-21.

Magri, Giorgio. 2009. A theory of individual-level predicates based on blind mandatory scalar implicatures. PhD dissertation, MIT.

Magri, Giorgio. 2011. Another argument for embedded scalar implicatures based on oddness in DE environments. Semantics and Pragmatics 4(6): 1-51.

Magri, Giorgio. 2013. An account for the homogeneity effects triggered by plural definites and conjunction based on double strengthening. Manuscript, CNRS.

Marty, Paul. 2017. Implicatures in the DP domain. PhD dissertation, MIT.

Marty, Paul. 2019a. Maximize Presupposition! and presupposition satisfaction. Snippets 37: 59-60.

Marty, Paul. 2019b. On the source of proper partitivity. In Proceedings of Sinn und Bedeutung 23, eds. M. T. Espinal et al., Vol. 2, 143-160. University of Konstanz.

Marty, Paul, and Jacopo Romoli. 2021. Presupposed free choice and the theory of implicatures. Linguistics and Philosophy. https://doi.org/10.1007/s10988-020-09316-5.

Meyer, Marie-Christine. 2013. Ignorance and grammar. PhD dissertation, MIT.

Meyer, Marie-Christine. 2014. Deriving Hurford's constraint. Semantics and Linguistic Theory 24: 577-596.

Palmer, Frank Robert. 1986. Mood and modality. Cambridge: Cambridge University Press.

Percus, Orin. 2006. Anti-presuppositions. In Theoretical and empirical studies of reference and anaphora: Toward the establishment of generative grammar as an empirical science, ed. A. Ueyama, 52-73. Japan Society for the Promotion of Science. Report of the grant-in-aid for scientific research (B), Project No. 15320052.

Percus, Orin. 2010. Antipresuppositions revisited. Handout from a talk given at CRISCO, Université de Caen. https://www.academia.edu/1468709/Antipresuppositions_Revisited_Handout_2010_Caen_ talk_.

Roberts, Craige. 2004. Context in dynamic interpretation. In Handbook of pragmatics, eds. Laurence R. Horn and Gregory Ward, 197-220. Malden: Blackwell. 
Romoli, Jacopo. 2012. Soft but strong: Neg-raising, soft triggers, and exhaustification. PhD dissertation, Harvard University.

Rooth, Mats. 1992. A theory of focus interpretation. Natural Language Semantics 1(1): 117-121.

Rooth, Mats E. 1985. Association with focus. PhD dissertation, University of Massachusetts at Amherst.

Rouillard, Vincent, and Bernhard Schwarz. 2017. Epistemic narrowing for Maximize Resupposition. In Proceedings of the North East Linguistic Society 47, eds. A. Lamont and K. Tetzloff, 1-14. Amherst: GLSA.

Saebo, Kjell Johan. 2004. Conversational contrast and conventional parallel: Topic implicatures and additive presuppositions. Journal of Semantics 21(2): 199-217.

Sarkar, Anoop. 1998. The conflict between future tense and modality: The case of will in English. University of Pennsylvania Working Papers in Linguistics 5(2): 91-117.

Sauerland, Uli. 2004. Scalar implicatures in complex sentences. Linguistics and Philosophy 27(3): 367-391.

Sauerland, Uli. 2008. On the semantic markedness of Phi-features. In Phi theory, eds. Daniel Harbour, David Adger, and Susana Béjar, 57-82. Oxford: Oxford University Press.

Sauerland, Uli, and Kazuko Yatsushiro. 2004. A silent noun in partitives. In Proceedings of the North East Linguistics Society 34, eds. K. Moulton and M. Woolf, 505-516. Amherst: GLSA.

Sauerland, Uli, and Kazuko Yatsushiro. 2017. Two nouns in partitives: Evidence from Japanese. Glossa 2(1): 1-29.

Schlenker, Philippe. 2009. Local contexts. Semantics and Pragmatics 2(3): 1-78. https://doi.org/10.3765/ sp.2.3.

Schlenker, Philippe. 2012. Maximize Presupposition and Gricean reasoning. Natural Language Semantics 20(4): 391-429.

Sharvit, Yael, and Jon Gajewski. 2008. On the calculation of local implicatures. In Proceedings of WCCFL 26, eds. C. Chang and H. Haynie, 411-419. Somerville: Cascadilla Proceedings Project.

Simons, Mandy. 2001. Disjunction and alternativeness. Linguistics and Philosophy 24: 597-619.

Singh, Raj. 2008. Modularity and locality in interpretation. PhD dissertation, MIT.

Singh, Raj. 2010. Oddness and ignorance inferences. Handout presented at Modularity Reading Group at MIT, 2010.

Spector, Benjamin, and Yasutada Sudo. 2017. Presupposed ignorance and exhaustification: How scalar implicatures and presuppositions interact. Linguistics and Philosophy 40(5): 473-517.

Sudo, Yasutada. 2016. The existential problem of scalar implicatures and anaphora across alternatives. In Empirical issues in syntax and semantics, Vol. 11, ed. Christopher Pinon, 225-244. Paris: CSSP.

Zamparelli, Roberto. 1998. A theory of kinds, partitives and of/z possessives. In Possessors, predicates and movement in the determiner phrase, eds. A. Alexiadou and C. Wilder, 259-304. Amsterdam: Benjamins.

Publisher's Note Springer Nature remains neutral with regard to jurisdictional claims in published maps and institutional affiliations.

\section{Authors and Affiliations}

\section{Paul Marty ${ }^{1}$ - Jacopo Romoli ${ }^{2}$}

$\triangle$ P. Marty

p.marty@ucl.ac.uk; url: https://www.ucl.ac.uk/pals/people/paul-marty

\section{J. Romoli}

jacopo.romoli@uib.no; url: http://www.jacoporomoli.com/

1 Division of Psychology and Language Sciences, University College London, 26 Bedford Way, London WC1H 0AP, United Kingdom

2 Department of Foreign Languages, University of Bergen, HF-bygget, Sydnesplassen 7, 5020 Bergen, Norway 